\title{
Expression of Glial Fibrillary Acidic Protein and Its Relation to Tract Formation in Embryonic Zebrafish (Danio rerio)
}

\author{
RIVA C. MARCUS AND STEPHEN S. EASTER, JR. \\ Neuroscience Program (R.C.M., S.S.E.) and Department of Biology (S.S.E.), \\ University of Michigan, Ann Arbor, Michigan 48109-1048
}

\begin{abstract}
To address possible roles of glial cells during axon outgrowth in the vertebrate central nervous system, we investigated the appearance and distribution of the glial-specific intermediate filament, glial fibrillary acidic protein (GFAP), during early embryogenesis of the zebrafish (Danio rerio). Immunopositive cells first appear at 15 hours, which is at the time of, or slightly before, the first axon outgrowth in the brain. Immunopositive processes are not initially present in a pattern that prefigures the location of the first tracts but rather are distributed widely as endfeet adjacent to the pia, overlying most of the surface of the brain with the exception of the dorsal and ventral midline. The first evidence for a specific association of immunopositive cells with the developing tracts is observed at 24 hours in the hindbrain, where immunopositive processes border axons in the medial longitudinal fasciculus. By 48 hours, immunopositive processes have disappeared from most of the subpial lamina and are found exclusively in association with tracts and commissures in three forms: endfeet, radially oriented processes, and tangentially oriented processes parallel to axons. This last form is particularly prominent in the transverse plane of the hindbrain, where they define the boundaries between rhombomeres. These results suggest that glial cells contribute to the development and organization of the central nervous system by supporting early axon outgrowth in the subpial lamina and by forming boundaries around tracts and between neuromeres. The results are discussed in relation to previous results on neuron-glia interactions and possible roles of glial cells in axonal guidance. 1995 Wiley-Liss, Inc.
\end{abstract}

Indexing terms: Brachydanio rerio, GFAP, intermediate filaments, axonal scaffold, fish glia

Glial cells are the major nonneuronal component in the nervous system, and they have been suggested as playing a role in early pattern formation and in the establishment of neural pathways. In culture, glial cells are preferred substrates for axon elongation (Noble et al., 1984; Fallon, 1985). Nonneural "primitive glial" cells also appear to provide a favorable substrate for early axon growth in vivo. A scaffold of primitive glia may be involved in the initial patterning of axonal pathways in the insect nervous system (Bastiani and Goodman, 1986; Jacobs and Goodman, 1989), and glial cell disruptions are sufficient to cause axon tract malformations (Bastiani and Goodman, 1986; Jacobs, 1993; Gorczyca et al., 1994). In vertebrates, the earliest tracts form superficially, and growth cones extend in contact with the endfeet of radial neuroepithelial cells (Singer et al., 1979; Kuwada, 1986; Wilson and Easter, 1991). Optic axons course along radial cell endfeet en route to their targets in the brain (Silver and Sidman, 1980; Silver, 1984; Silver and
Rutishauser, 1984; Bovolenta and Mason, 1987; Colello and Guillery, 1992), and growth cones are associated with radial cells in the chick tectum (Vanselow et al., 1989) and the hamster cerebral cortex (Norris and Kalil, 1991). Other evidence suggests that certain glial tissues form boundaries inhibitory to axon growth. Examples of structures that function as barriers include the roofplate of the spinal cord and tectum (Joosten and Gribnau, 1989; Snow et al., 1990) and the glial "knot" located in the rostral midline of the optic chiasm (Silver, 1984; Silver et al., 1987). Thus nonneural cells may contribute to the patterning and formation of the nervous system by acting as guides or barriers at critical stages of development (Silver et al., 1993).

Accepted January 6, 1995

Address reprint requests to Dr. Riva C. Marcus, Department of Pathology, Columbia University College of Physicians and Surgeons, 630 West 168th Street, New York, NY 10032. 
Although embryonic nonneural cells have often been called "primitive glia," their glial identity is uncertain because it has often been based on morphological criteria alone (e.g., Ramón y Cajal, 1911; Schmechel and Rakic, 1979). Electron microscopic studies of early axon outgrowth identified the neuroepithelial endfeet contacted by growth cones as belonging to "primitive radial glia" (Singer et al., 1979; Silver, 1984; Kuwada, 1986; Wilson and Easter, 1991), but in the absence of any independent evidence, this nomenclature must be considered speculative. The recent development of cell-specific markers provides a useful method to study identified populations of cells, and in this study we use the glial-specific intermediate filament, glial fibrillary acidic protein (GFAP; Eng et al., 1971), to identify presumptive glia during early stages of development. Antisera to GFAP have been used extensively to visualize mature and developing glial cells in many species (monkey: Levitt and Rakic, 1980; cat: Silver et al., 1993; mouse: Bovolenta et al., 1987; Xenopus: Szaro and Gainer, 1988; fish: Levine 1989; Nona et al., 1989).

To examine possible roles of glia in axon outgrowth, it is important to investigate the appearance and distribution of these cells in a system in which the development of the earliest neurons and their axonal tracts is well established. The embryonic zebrafish brain provides such a system. The first growth cones appear at 16 hours in the fore- and midbrain (Ross et al., 1992) and at 18 hours in the hindbrain (Mendelson, 1986). As development continues, neurons and axons are added in a stereotyped manner such that by 24 hours a simple scaffold of tracts is present (Chitnis and Kuwada, 1990; Wilson et al., 1990; Ross et al., 1992). Between 24 and 48 hours many more axons are added, and most of the additional axons join preexisting tracts rather than pioneer new ones (Wilson et al., 1990). Thus, the embryonic zebrafish provides a relatively simple vertebrate model in which to investigate the differentiation, distribution, and roles of glial cells during both initial axon outgrowth and subsequent development.

In this paper, we describe the appearance of GFAPpositive cells in the embryonic vertebrate brain, with particular emphasis on their relation to early tracts. Some of these results have appeared as abstracts (Marcus and Easter, 1990; Marcus et al., 1990).

\section{MATERIALS AND METHODS General}

Adult and embryonic zebrafish (Danio rerio) were obtained from our own breeding colony. Breeders were maintained at $28.5^{\circ} \mathrm{C}$ on a 14 -hour-light $/ 10$-hour-dark cycle. Fertilized eggs were collected and raised in an embryorearing solution (ERS: $0.1 \% \mathrm{NaCl}, 0.003 \% \mathrm{KCl}, 0.0163 \%$ $\mathrm{MgSO}_{4}, 0.004 \% \mathrm{CaCl}_{2} \cdot 2 \mathrm{H}_{2} \mathrm{O}$ ) at $28.5^{\circ} \mathrm{C}$. The time of fertilization was estimated based on the number of cell divisions at the time of sorting (Westerfield, 1989). Ages are given in hours after estimated time of fertilization. Embryos were dechorionated and anesthetized in approximately $0.03 \%$ tricaine methanesulfonate (Sigma) prior to experimental procedures.

\section{Primary antibodies}

Three antibodies against GFAP were used. The first was a polyclonal antibody generated against GFAP from goldfish brain (anti-gGFAP, kindly provided by $\mathrm{S}$. Nona) that recognizes GFAP in both goldfish (Nona et al., 1989) and rat (Shehab et al., 1989). The second was a commercially available polyclonal antibody (Dako-GFAP) generated against GFAP from bovine hoof (Dakopatts). The third was a monoclonal antibody (zrf-1, kindly provided by M. Westerfield) that labels radial cells in embryonic zebrafish (Trevarrow et al., 1990). This antibody was generated against a basal lamina and cytoskeleton preparation from adult zebrafish hindbrains and spinal cords (Trevarrow, 1988), and we characterize it further in the Results. The HNK-1 antibody (kindly provided by C. Stern) recognizes an antigen expressed on a variety of cell adhesion molecules (Kruse et al., 1984) and was used to visualize the location of developing tracts, as shown elsewhere (Metcalfe et al., 1990; Wilson et al., 1990; Ross et al., 1992).

\section{Tissue preparations for electrophoresis}

Antibody immunoreactivities were visualized on Western blots of protein extracts separated by sodium dodecyl sulfate-polyacrylamide gel electrophoresis (SDS-PAGE). Two different kinds of protein preparations were made. An adult cytoskeletal preparation was obtained by a modification of methods described by Chiu and Norton (1982) and by Quitschke and Schechter (1986). Adult zebrafish were anesthetized in a solution of $0.2 \%$ tricaine, and their brains were removed and homogenized in an ice-cold solution containing $50 \mathrm{mM}$ Tris-HCl (pH 6.8), $2 \mathrm{mM}$ EDTA, $2 \mathrm{mM}$ EGTA, 0.5\% (vol/vol) Triton X (octyl-phenoxy-polyethoxyethanol, Sigma), and $30 \% \mathrm{w} / \mathrm{v}$ sucrose to remove Tritonsoluble proteins. The Triton-insoluble proteins were resuspended in $0.4 \%$ SDS and stored at $-20^{\circ} \mathrm{C}$ until used for electrophoresis.

A total protein tissue homogenate was prepared from both embryonic and larval zebrafish. For the embryonic preparation, proteins were extracted from embryos between 18 and 48 hours old in which the yolk was removed. For the larval preparation, zebrafish (7-9 days old) were cut transversely, and proteins were extracted from the rostral one-third. Briefly, the embryonic and larval tissues were homogenized in a boiling solution of $62.5 \mathrm{mM}$ Tris- $\mathrm{HCl}(\mathrm{pH}$ 6.8), $10 \%$ glycerol, and $2 \%$ SDS and then centrifuged at $13,000 \mathrm{~g}$ for 15 minutes and the proteins precipitated by mixing the supernatant with five volumes of ice-cold acetone. The proteins were resuspended in a small volume of Tris buffer containing glycerol and SDS and stored at $-20^{\circ} \mathrm{C}$. Protein contents of all three tissue preparations were determined by using the BCA protein assay reagent (Pierce)

\section{Gel electrophoresis and Western blots}

Tissue samples were diluted in sample buffer containing $62.5 \mathrm{mM}$ Tris-HCl (pH 6.8), 10\% glycerol, $2 \%$ SDS, 1-5\% $\beta$-mercaptoethanol plus bromophenol blue and boiled for 5 minutes prior to loading. Twenty micrograms of the adult cytoskeletal preparation or $50 \mu \mathrm{g}$ of either the embryonic or larval preparations were added per lane. Proteins were separated in $10-\mathrm{cm}$ long, $12 \% \mathrm{w} / \mathrm{v}$ polyacrylamide gels (Bio-Rad) according to the Laemmli buffer system (Laemmli, 1970) and then transferred to nitrocellulose $0.2 \mu \mathrm{m}$; Schleicher and Schuell) in transfer buffer containing 25 $\mathrm{mM}$ Tris-HCl, $192 \mathrm{mM}$ glycine, and $20 \% \mathrm{v} / \mathrm{v}$ methanol.

\section{Immunolabeling of Western blots}

Nitrocellulose strips were blocked in Tris buffered saline (TBS: $0.1 \mathrm{mM}$ Tris-HCl, $0.9 \% \mathrm{NaCl}, \mathrm{pH} 7.4$ ) plus $5 \%$ nonfat dry milk (NFDM) for 1 hour followed by incubation over- 
night at $4^{\circ} \mathrm{C}$ in the primary antibodies diluted in TBS containing 5\% NFDM and 5\% normal goat serum. After washes in TBS, the strips were incubated first in either biotin-conjugated goat anti-mouse IgG (for zrf-1) or biotinconjugated goat anti-rabbit IgG (for gGFAP and DakoGFAP) for 90 minutes followed by incubation in a peroxidase-conjugated avidin-biotin complex (ABC kit, Vector Laboratories) for 1 hour. Labeling was developed by incubating the strips in TBS containing $0.05 \%$ 4-chloro-1-naphthol (Sigma) and $0.015 \% \mathrm{H}_{2} \mathrm{O}_{2}$ for up to 30 minutes. The nitrocellulose strips were air dried and immediately photographed. All steps were carried out at room temperature unless otherwise stated. In control experiments, the primary antibodies were replaced by nonimmune sera from rabbits.

\section{Immunocytochemical labeling}

Embryos between 12 and 48 hours old were fixed in either $4 \%$ formalin buffered with Pipes $(0.1 \mathrm{M}$ disodium salt [Sigma], plus $2 \mathrm{mM}$ EGTA and $1 \mathrm{mM} \mathrm{MgSO}_{4}, \mathrm{pH}$ 6.95) or $2 \% \mathrm{w} / \mathrm{v}$ trichloroacetic acid (TCA) for 4 hours at room temperature. Frozen sections $(10-20 \mu \mathrm{m})$ were washed in phosphate buffered saline (PBS; pH 7.4) containing $0.3 \%$ Triton $\mathrm{X}$ followed by incubation for 30 minutes in PBS plus Triton X containing $10 \%$ normal goat serum and $0.05 \%$ bovine serum albumin to block nonspecific binding. Primary antibodies diluted in blocking buffer were applied to the slides either overnight at $4^{\circ} \mathrm{C}$ or for 90 minutes at room temperature. Secondary antibodies (peroxidase-conjugated goat anti-rabbit IgG for anti-gGFAP and Dako-GFAP or goat anti-mouse IgG for zrf-1) were applied for 60 minutes at room temperature. In some cases, a biotin-conjugated secondary antibody was used, followed by incubation with the Vector $\mathrm{ABC}$ kit for 30 minutes at room temperature. Brown peroxidase labeling was obtained in the presence of $0.8 \mathrm{mg} / \mathrm{ml}$ diaminobenzidine (DAB; Sigma) plus $0.005 \%$ hydrogen peroxide. A blue reaction product was obtained when the reaction proceeded in the presence of a $0.05 \%$ solution of $\mathrm{NiCl}_{2}$.

Some embryos were prepared for wholemount immunocytochemistry. In certain cases, embryos were pinned down in a Sylgard-coated dish, and the eyes, yolk sac, and skin overlying the brain were dissected away by using sharpened tungsten needles. Briefly, embryos were washed in PBS plus $0.5 \%$ Triton $\mathrm{X}$, preincubated in blocking buffer for 3 hours at room temperature, and incubated in the primary antibody overnight at $4^{\circ} \mathrm{C}$. The next day, embryos were washed in buffer six times for 1 hour each followed by incubation in peroxidase-conjugated secondary antibody overnight at $4^{\circ} \mathrm{C}$. Following six washes in buffer, embryos were incubated in $0.8 \mathrm{mg} / \mathrm{ml}$ of $\mathrm{DAB}$ for 30 minutes and reacted by adding $\mathrm{H}_{2} \mathrm{O}_{2}$ with or without $\mathrm{NiCl}_{2}$. The relationship of GFAP-immunoreactive cells to developing tracts was visualized by double labeling embryos with both antigGFAP and HNK-1. HNK-1 labeling was indirectly visualized with a goat anti-mouse IgM secondary antibody conjugated to peroxidase.

Selected wholemounts were dehydrated with $95 \%$ ethanol, embedded in glycol methacrylate, and sectioned at 3-10 $\mu \mathrm{m}$.

\section{Electron microscopy}

All embryos prepared for electron microscopy were dissected prior to immunolabeling and were not exposed to Triton $\mathrm{X}$ in any of the later steps. Following reaction as wholemounts, embryos were immersed in $3.5 \%$ glutaraldehyde in $0.1 \mathrm{M} \mathrm{PO}_{4}$ buffer for 2 hours. The tissue was postfixed in $1 \%$ osmium tetroxide in $0.075 \mathrm{M} \mathrm{PO}_{4}$ buffer for 1 hour, washed in distilled water and $0.05 \mathrm{M}$ maleate buffer ( $\mathrm{pH} 6.0$ ), and stained en bloc in $2 \%$ uranyl acetate in maleate buffer for 1 hour. After washes in maleate buffer, the tissue was dehydrated in alcohols, cleared in propylene oxide, and embedded in Epon/Araldite.

Semithin sections were stained with toluidine blue. Ultrathin sections were mounted on formvar-coated one-hole grids and viewed on a Philips 300 electron microscope. No adjustments for shrinkage were made in estimating calibration scales.

\section{DiI and HRP labeling of neuroepithelial cells}

Neuroepithelial cells in zebrafish embryos of various ages were labeled either with horseradish peroxidase (HRP; type VI, Sigma) or the lipophilic dye, DiI (1,1'-dioctadecyl$3,3,3^{\prime}, 3^{\prime}$, tetramethylindocarbocyanine perchlorate; Molecular Probes; Honig and Hume, 1986). For HRP labeling, a small volume of $5 \% \mathrm{HRP}$ in distilled $\mathrm{H}_{2} \mathrm{O}$ was pressureinjected from a micropipette under visual control, directly into the brains, near the ventricular surface, of anesthetized embryos suspended in 3\% agar in ERS. Following a 15-minute survival time, embryos were fixed in $0.1 \mathrm{M} \mathrm{PO}_{4}$ buffer containing $2.5 \%$ glutaraldehyde and $2 \%$ formalin plus 5\% DMSO for 2 hours at room temperature. HRPlabeled cells were visualized by incubating embryos in DAB plus $\mathrm{H}_{2} \mathrm{O}_{2}$.

DiI labeling was performed in embryos fixed in $4 \%$ phosphate buffered formalin. Cells were labeled either by placing small crystals of DiI on the ventricular surface of embryos, which had the skin overlying the ventricles removed, or by pressure-injection of a small amount of DiI dissolved in $0.25 \% N, N$-dimethylformamide either into the brain or onto the ventricular surface. Fluorescently labeled cells were photoconverted to a permanent brown reaction product by photoexcitation of the dye in the presence of $0.05 \%$ DAB (Sandell and Masland, 1988). Some embryos were embedded in glycol methacrylate and sectioned. Labeling with HRP often resulted in singly labeled cells, and applications of DiI to the ventricular surface yielded larger numbers of labeled cells; therefore, both methods were used.

\section{RESULTS Specificity of the antibodies}

The specificities of the antibodies had to be established independently in view of their different origins (see Methods). The specificities were assessed on Western blots and tissue sections.

The Western blots are shown in Figure 1. All three antibodies labeled a major band of apparent molecular weight $51 \mathrm{kDa}$ as well as a second band at $45 \mathrm{kDa}$. The Dako-GFAP antibody labeled these same two bands as well as proteins of higher and lower molecular weights, similar to a report for this antibody in adult goldfish (Levine, 1989). The $51 \mathrm{kDa}$ band matches the molecular weight of fish GFAP given in other reports (Quitschke et al., 1985; Maggs and Scholes, 1986; Levine, 1989; Nona et al., 1989), thereby supporting the assertion that all three antibodies recognize zebrafish GFAP. Although antibodies against GFAP only label a single band in mammals (Dahl et al., 1985; Quitschke et al., 1985), in fish two labeled bands have been reported by 
others (Dahl et al., 1985; Quitschke et al, 1985; Levine, 1989).

Both anti-gGFAP and zrf-1 labeled sections of adult and embryonic zebrafish similarly (data not shown). For example, in the adult visual pathway, the antibodies labeled

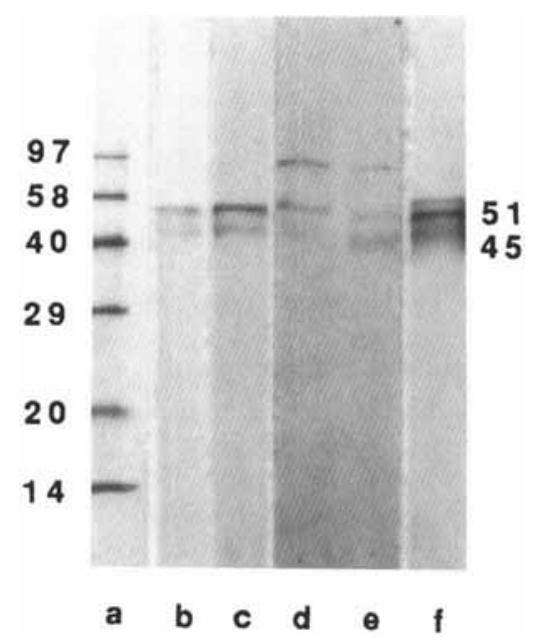

Fig. 1. Western blots of zebrafish proteins stained by glial fibrillary acidic protein (GFAP) antibodies. Lane a shows molecular weight standards separated by sodium dodecyl sulfate-polyacrylamide gel electrophoresis (SDS-PAGE). Molecular weights are indicated by the arrows and numbers on the left. Lanes $\mathbf{b}$, $\mathbf{c}$, and $\mathbf{f}$ correspond to Western blots of extracts of intermediate filaments from adult zebrafish brain and were stained with zrf-1, anti-gGFAP, and Dako-GFAP, respectively. Lanes $\mathbf{d}$ and $\mathbf{e}$ are Western blots of larval (d) and embryonic (e) proteins stained with anti-gGFAP. The molecular weights of the two bands seen in b-e are indicated by the arrows and numbers on the right. An additional higher band was sometimes observed (e.g., in $\mathrm{d}$ and $\mathrm{e}$ ), but this band was also seen on blots stained with normal rabbit serum and therefore represents nonspecific binding. Dako-GFAP (f) stained bands in addition to the $51-\mathrm{kDa}$ and $54-\mathrm{kDa}$ bands observed with zrf-1 and anti-gGFAP. This figure was digitally scanned, and the contrast in lanes $d$ and e was enhanced.

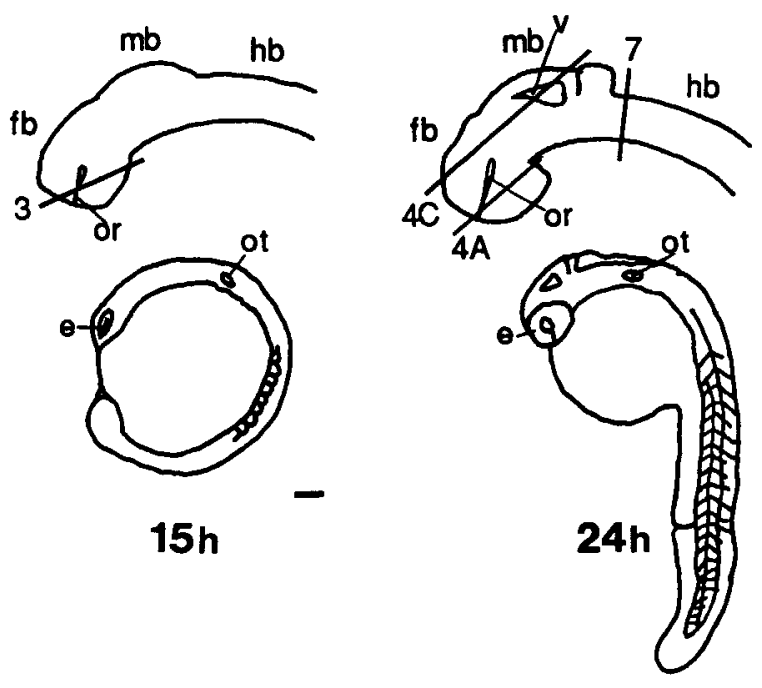

Fig. 2. Camera lucida drawings show brains (upper) and whole embryos (lower) at 15,24 , and 48 hours old. The brains and embryos are viewed laterally and are oriented so that the rostral hindbrain is horizontal. The lines denote planes of section for figures as indicated.e, radial glial fibers in the optic tectum and optic tract but not in the optic nerve, confirming earlier work on the distribution of glial cells in adult fish (Dahl and Bignami, 1973; Dahl et al., 1985; Maggs and Scholes, 1986; Levine, 1989 ; Nona et al., 1989). In contrast, Dako-GFAP weakly labeled glial cells in adults, and in embryos it also labeled processes that were HNK-1 positive and were therefore presumed to be neural.

Thus, both the immunoblots and the antibody labeling in the adult support the conclusion that all three antibodies recognize GFAP in the zebrafish. Because Dako-GFAP labeled additional bands in the Western blots and neural processes in the embryo, this antibody was not used further.

\section{Time course of GFAP expression}

Wholemounts and frozen sections from embryos between 12 and 48 hours old were examined immunocytochemically. Schematic diagrams of embryonic zebrafish at the ages discussed in the Results are presented in Figure 2. Both anti-gGFAP and zrf-1 labeled embryos similarly; therefore, structures labeled by either are referred to simply as GFAP positive in the text.

GFAP immunoreactivity first appears in the brain at 15 hours (Fig. 3), which is at about the same time as the first differentiated neurons (Ross et al., 1992). Lightly labeled processes are located laterally along the superficial surface of the central nervous system (CNS), and a few GFAPpositive processes extend more deeply. The first axons course in the subpial region, the location where the GFAP labeling first appears. The GFAP-positive processes belong to radially oriented cells because the deeper processes are oriented perpendicularly to the surface and are occasionally seen to join the labeled superficial processes (Fig. 3 , inset). The widespread distribution of GFAP immunoreactivity implies that it must appear in places devoid of axons because axons are few and in known locations (Ross et al., 1992). This conclusion was confirmed by double labeling with both anti-gGFAP and HNK-1. GFAP-positive pro-

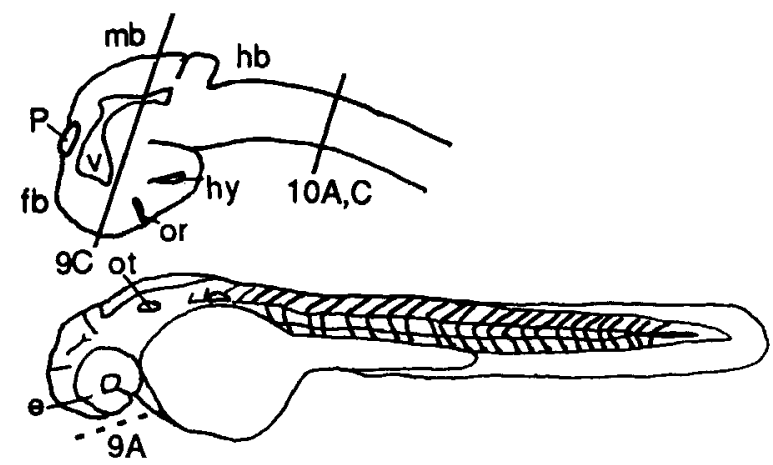

$48 h$

eye; fb, forebrain; hb, hindbrain; hy, hypothalamus; mb, midbrain; or, optic recess; ot, otocyst; $P$, pineal; $v$, ventricle. Scale bar $=25 \mu \mathrm{m}$ for brains, $100 \mu \mathrm{m}$ for embryos. 


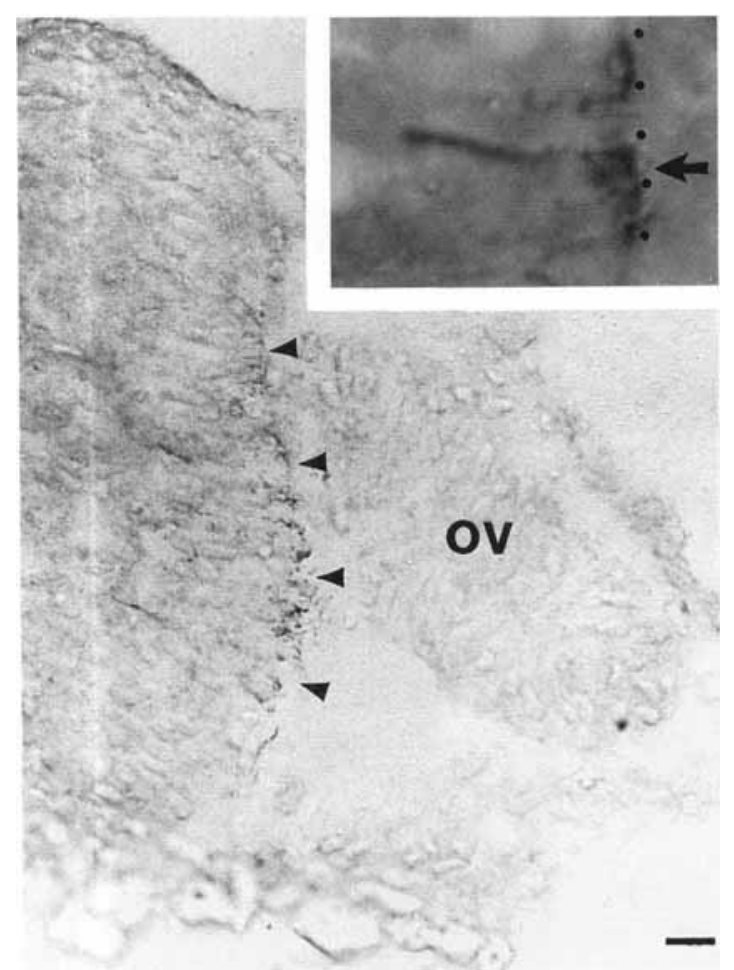

Fig. 3. Frozen section from a 15-hour-old zebrafish embryo labeled with anti-gGFAP. Dorsal is up; the plane of section is indicated in Figure 2. GFAP-positive processes are localized to the lateral edge of the brain (arrowheads). The inset is a higher magnification of GFAPpositive labeling in an adjacent section. The arrow points to an endfoot that is attached to a labeled process oriented perpendicularly to the surface. The dotted line indicates the edge of the brain. ov, optic vesicle. Scale bar $=10 \mu \mathrm{m}, 2 \mu \mathrm{m}$ in inset.

cesses exist in regions of the CNS that are both HNK-1 negative and positive (data not shown).

At 24 hours, GFAP-positive labeling is found throughout the brain, except along the dorsal and ventral midline (Fig. 4). The label is restricted to the basal processes and endfeet of radially oriented cells contacting the subpial surface of the brain. DiI and HRP were used to visualize the morphology of cells with processes that terminate along the superficial lamina. At all ages investigated, labeled cells extended from the ventricle to the superficial surface of the brain, where the basal processes enlarged and formed endfeet (Fig. 5) similar to those revealed by the antibody labeling. Based on the similarity between the morphology of the GFAP-labeled endfeet and the endfeet of the DiI-and HRP-labeled cells, we identify the cells labeled by the antibodies at 24 hours as radial glia.

At 24 hours, a small number of identifiable tracts and commissures are present in the brain (Chitnis and Kuwada, 1990; Wilson et al., 1990; Fig. 6, inset). GFAP-labeled processes are more broadly distributed than the axon scaffold, and these processes are located in regions both with and without developing tracts. For instance, GFAPpositive processes are located in the brain in the tract of the anterior commissure (TAC) and the tract of the postoptic commissure (TPOC; Fig. 4) and throughout the dorsal diencephalon, which contains only a few axons from the dorsoventral diencephalic tract (DVDT) and tract of the posterior commissure (TPC) at this time. Moreover, GFAP is absent from the midline, including regions containing the dorsal and ventral commissures, indicating that the presence of GFAP-positive processes is not essential for the development of commissures. Thus, GFAP-positive glial cells in the zebrafish are not distributed in a pattern that prefigures the first axon pathways

The earliest tracts are located superficially; therefore, laterally located tracts develop in regions containing GFAPpositive endfeet. Possible interactions between developing tracts and GFAP-immunolabeled processes were investigated ultrastructurally (Fig. 6). In electron micrographs, two types of labeled processes were observed. One includes wide, columnar endfeet, closely apposed to one another, and distributed throughout the fore- and midbrain. Label does not completely fill these columnar endfeet, but rather is concentrated near cell membranes along both the basal and lateral surfaces. In some regions (e.g., Fig. 6B,D), all or nearly all cells were labeled. The second type of labeled process includes smaller, more loosely packed processes, some of which extend to the pial surface, where they expand in contact with the basal lamina. They are found in tracts such as the TAC (Fig. 6A,C), where they are intermixed with unlabeled processes of similar morphology. Some of the unlabeled ones are presumably axons, but many must be endfeet because they are seen in contact with the basal lamina, where axons are not generally found (Wilson et al., 1990; Wilson and Easter, 1991).

A different kind of relationship between GFAP-positive processes and developing tracts was observed in the hindbrain (Fig. 7). The medial longitudinal fasciculus (MLF) was separated from the cellular region of the brain by labeled processes that seemed to incase the tract. Other GFAP-positive, radially oriented processes contact the basal lamina on the subpial surface of the brain outside of the region containing the MLF. The presence of nonradial, GFAP-positive processes around axons in the MLF suggests an active association of axons and glia, in which the axons have influenced a change in glial morphology.

The pattern of GFAP-immunopositive cells is quite different by the end of the second day of development. First, GFAP-positive processes are no longer spread broadly along the lateral subpial surface; instead, they are concentrated in and around tracts and commissures. Second, a new class of labeled processes has been added; these processes are oriented parallel to the pial surface and to axons in tracts and commissures.

The condensation of primitive glial processes in and around tracts and commissures is evident in both wholemounts and sections (Figs. 8-10). Wholemounts labeled for either GFAP or with the HNK-1 antibody to label axons have quite similar patterns of labeling (Figs. 8, 9A,B), but not all tracts are equally invested with glial processes. The TPC, the MLF, and the peripheral nerves are most heavily GFAP positive, and the other tracts less so. Among the less heavily labeled tracts, the TPOC is labeled more than the TAC (Fig. 9C,D). The commissures and the peripheral motor nerves become labeled only after they develop because they were unlabeled at 24 hours, a time when both contained axons (Myers et al., 1986; Wilson et al., 1990).

GFAP-positive processes running parallel to axons are observed in some tracts and commissures such as the THC and TPC (Figs. 8A, 9A,B). The appearance of GFAPlabeling in commissures is best illustrated in the hindbrain (Fig. 11A), where dorsoventral palisades of GFAP-positive processes near the rhombomeric borders form the "glial 

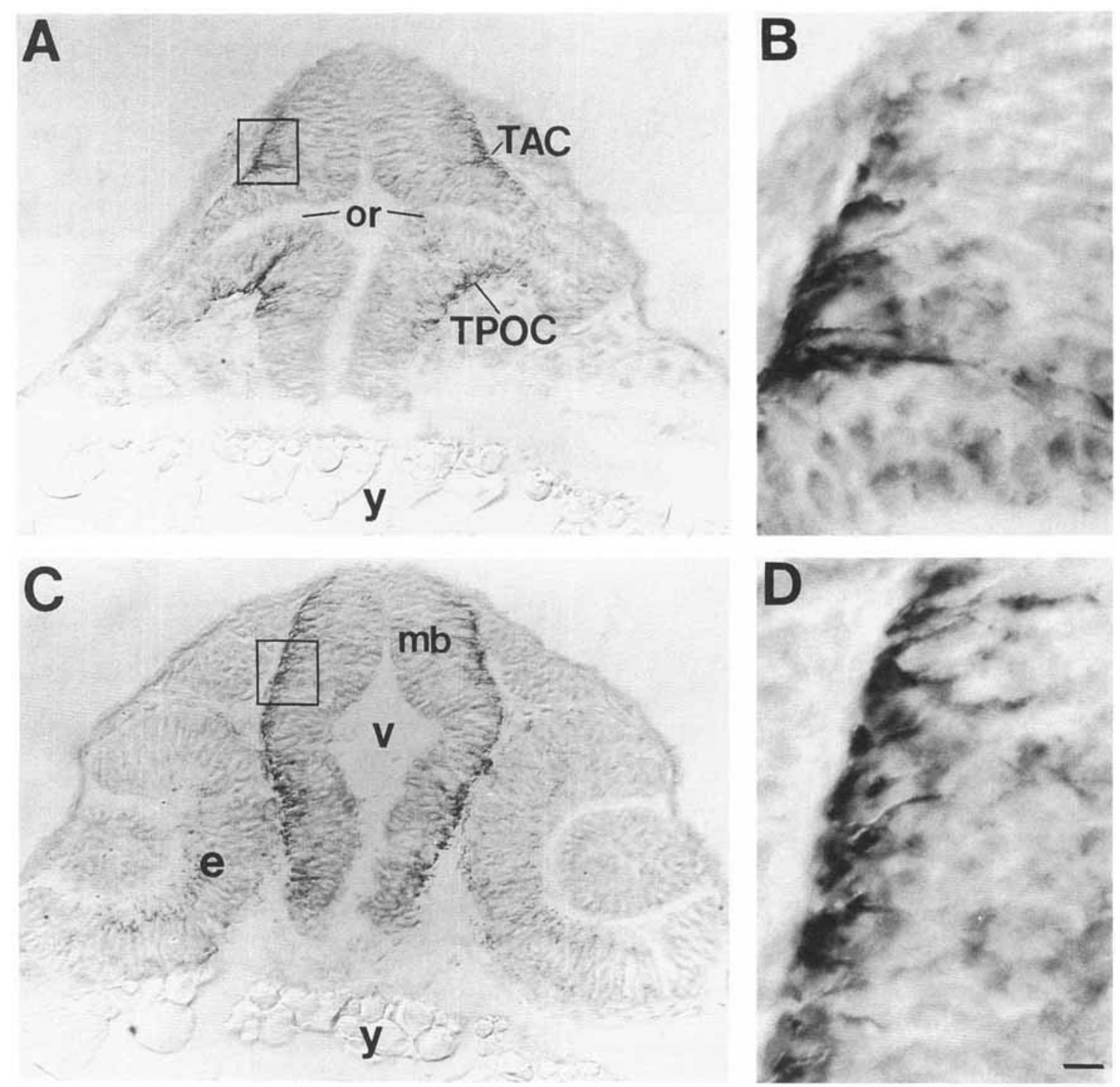

Fig. 4. Anti-gGFAP labeling in frozen sections from a 24-hour-old embryo. Dorsal is up; the planes of section are indicated in Figure 2. $\mathbf{A}$ and $\mathbf{C}$ are sections from the same embryo, and $\mathbf{B}$ and $\mathbf{D}$ are higher magnifications of the boxes in $A$ and $C$, respectively. Label is located laterally in the basal processes and endfeet of radially oriented cells.

curtains" described elsewhere (Trevarrow et al., 1990), and labeled processes cross the ventral midline (Figs. 10A,B, 11). These processes are interspersed among commissural axons, indicating that these processes run parallel to, and are in direct contact with, commissural axons in the border regions located between rhombomeres. Application of DiI to the fourth ventricle labels cells that send processes across the ventral midline and probably represent the GFAPpositive cells (Fig. 10C,D). Alternatively, the DiI-labeled cells may represent differentiating neurons that have extended axons prior to migration of the cell body away from the ventricle, possibly the dorsal commissural neurons (Trevarrow et al., 1990). This latter possibility seems less likely because the earliest tracts to develop in the embryonic zebrafish are located superficially (Wilson et al., 1990) in contrast to the deep location of the dorsoventrally oriented processes of the DiI-labeled cells. In addition, in
Note the absence of GFAP-positive labeling at the dorsal and ventral midline. e, eye; $\mathrm{mb}$, midbrain; or, optic recess; TAC, tract of the anterior commissure; TPOC, tract of the postoptic commissure; $v$, ventricle; $y$, yolk. Scale bar $=10 \mu \mathrm{m}$ in A,C, $5 \mu \mathrm{m}$ in B,D.

studies in which cells expressing neural antigens still assumed a neuroepithelial morphology, the cell nuclei were located near the pial, not the ventricular, surface (Cochard and Paulin, 1984; Sechrist and Bronner-Fraser, 1991; Easter et al., 1993).

\section{GFAP labeling in the POC-optic chiasm junction}

The first axons in the POC appear at about 24 hours (Wilson et al., 1990, unpublished observations). The first retinal axons arrive between 34 and 36 hours on the anterior edge of the POC (Stuermer, 1988; Burrill and Easter, 1991), where they form the optic chiasm. These two groups of axons-those in the POC and those in the chiasm-have different origins and destinations but course in close proximity to one another. We examined the develop- 

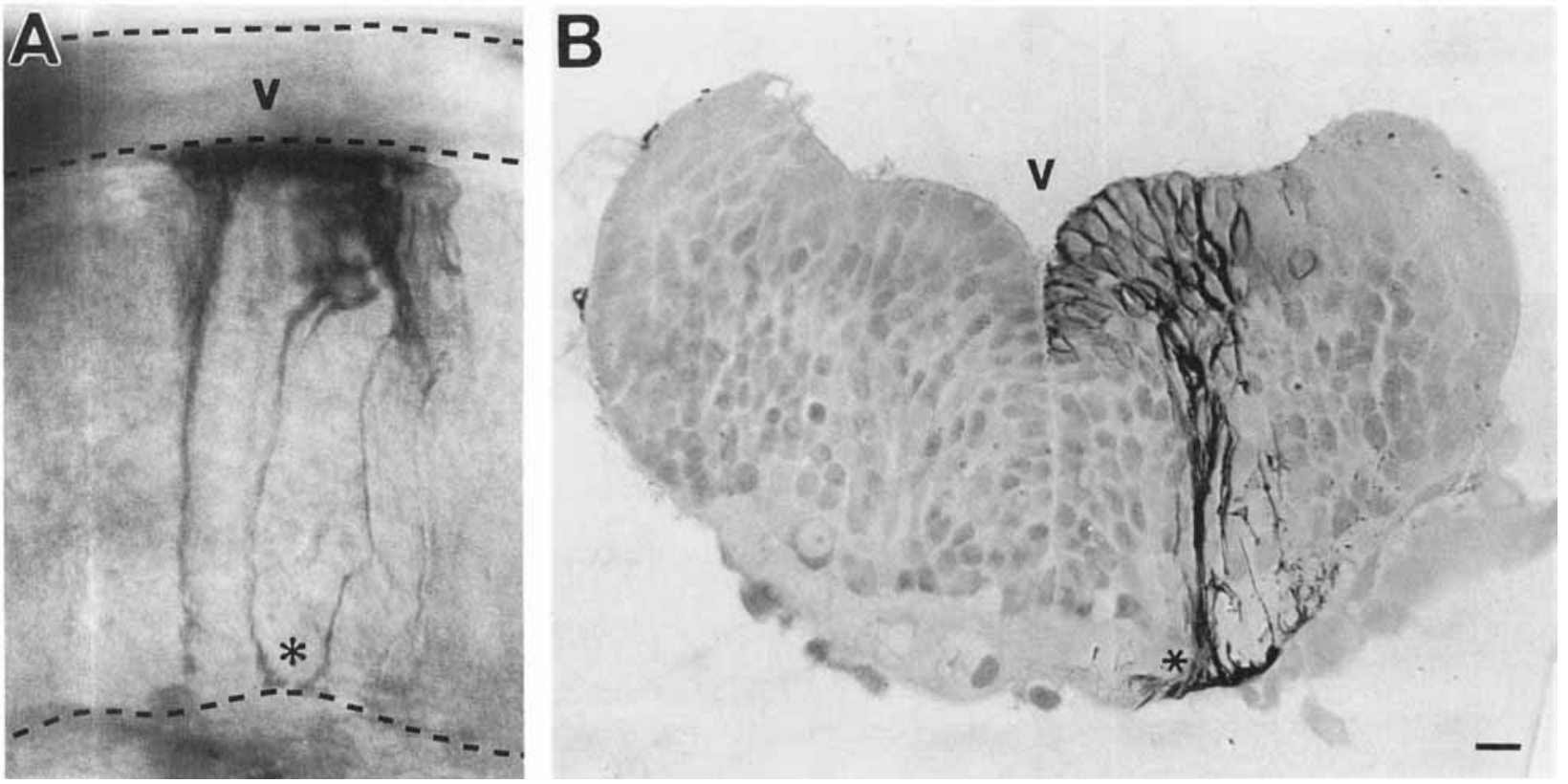

Fig. 5. Lipophilic dye (DiI)-labeled neuroepithelial cells. Dorsal is up. A: Lateral view of DiI-labeled cells in the hindbrain of a wholemounted 36-hour-old embryo. Anterior is to the left; the edges of the brain are demarcated by the dashed lines. B: Transverse section through the hindbrain of a 48-hour-old embryo labeled with DiI as a wholemount, then sectioned and counterstained. Labeled cells extend from the ventricular to the subpial surface of the brain, where their basal processes enlarge and form characteristic endfeet (asterisk). Similarly labeled cells were observed at all ages examined between 15 and 48 hours. $v$, location of IVth ventricle. Scale bar $=10 \mu \mathrm{m}$. ment of the chiasm with particular attention to GFAPpositive processes that might be involved in separating the two groups.

Although GFAP-positive processes are present at the ventral diencephalon when the optic chiasm forms, they are not intimately associated with the optic fibers. Figure 12A is an electron micrograph of a sagittal section through a 37-hour-old embryo labeled with anti-gGFAP. The optic axons were identified by tracing them from the optic stalk in electron micrographs of serial sections. Approximately 60 axons from each eye have reached the midline. GFAPpositive processes are seen along the superficial (ventral) and posterior edges of the POC. The optic axons are not contacted by any GFAP-positive processes, and they are separated from axons in the POC by a cellular region, $1-2-\mu \mathrm{m}$ wide, that is GFAP-negative. The GFAP-positive processes bordering the $\mathrm{POC}$ resemble those around the MLF in the hindbrain at 24 hours. Moreover, the association of GFAP-labeled processes with the already established POC, but not the developing optic chiasm, reinforces the previous observations that GFAP-positive processes are not present at the midline prior to the arrival of axons.

By 48 hours, the optic chiasm is separated from the POC by glial processes (Fig. 12B). GFAP-positive endfeet contact the basal lamina, and thinner, GFAP-positive processes extend into the brain. A labeled endfoot and process are located on the posterior edge of the POC, as was observed at 37 hours. In addition, a labeled process is located at the border between the optic axons and the POC (Fig. 12B, arrowheads) in contrast to the unlabeled region separating these tracts at 37 hours. Thus, GFAP-positive processes separate bundles of axons from different origins and from the cellular, axon-free regions in the brain. The appearance of GFAP immunoreactivity between the optic axons and the
POC between 37 and 48 hours suggests that the association of GFAP-immunoreactive processes with the optic chiasm develops in response to the arrival of the optic axons at the ventral midline.

\section{Summary}

GFAP-positive processes first appear at 15 hours, at or slightly before the first axon outgrowth in the brain. At 24 hours, GFAP-positive radial cells are widely distributed throughout the brain, with the exception of the ventral and dorsal midline. The first evidence for a specific association of GFAP-positive cells with the developing tracts was observed in the hindbrain at 24 hours, and by 48 hours, GFAP-positive processes and endfeet were concentrated only in those regions containing tracts. Therefore, many of the cells that expressed GFAP at 15 and 24 hours no longer expressed it at 48 hours. In addition to GFAP-positive radial processes, labeled processes oriented parallel to nerve fibers were observed in some tracts, including the dorsal and ventral commissures, but in all such cases, the GFAPpositive processes appeared after the axons. Finally, GFAPpositive processes were observed at the borders between the neuropil and cellular regions in the brain and between bundles of axons from distinct origins.

\section{DISCUSSION GFAP expression in fish glia}

The most abundant intermediate filament in nonneuronal cells of the adult central nervous system is GFAP. Comparative studies have shown that the protein is highly conserved, and in most species, one major polypeptide of approximate molecular weight $51 \mathrm{kDa}$ is observed, al- 

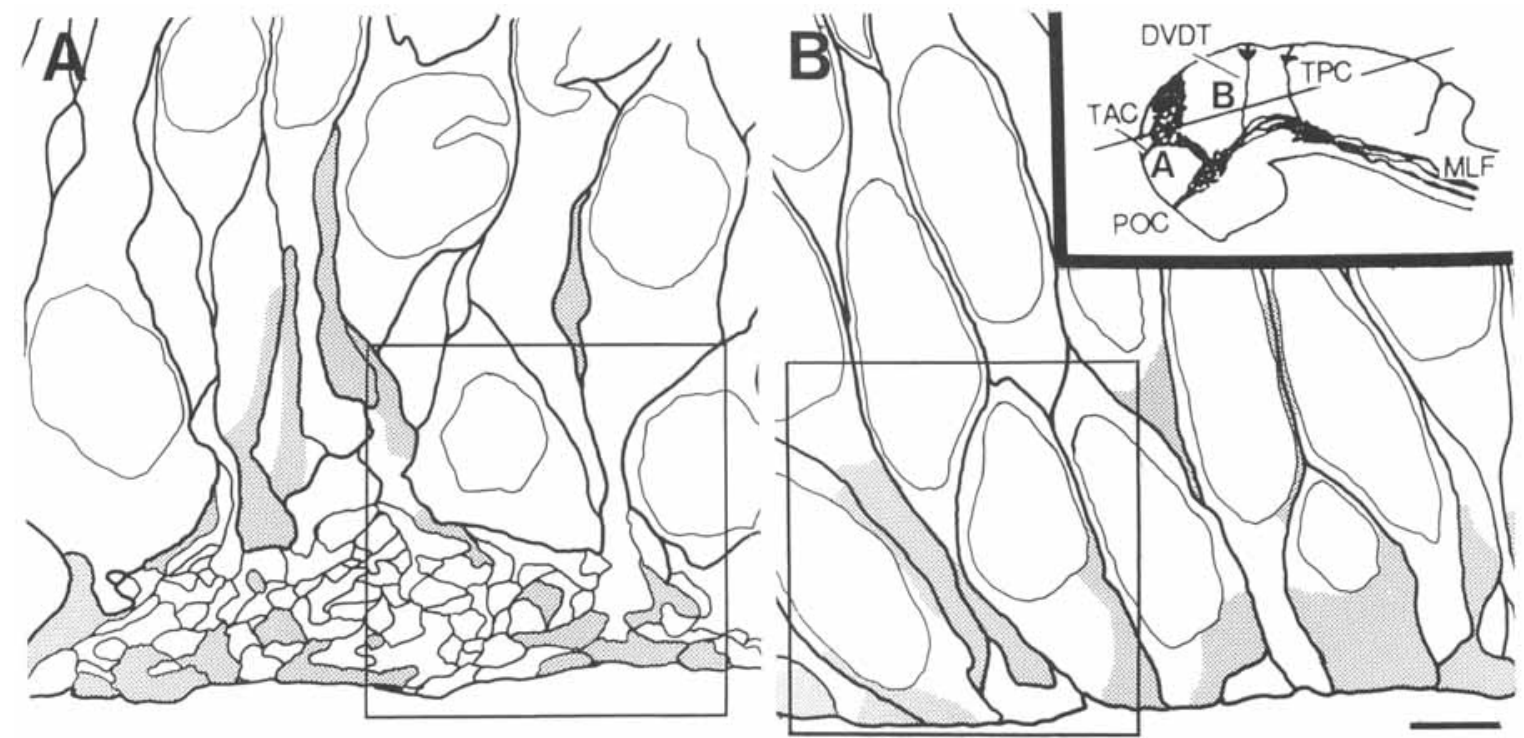

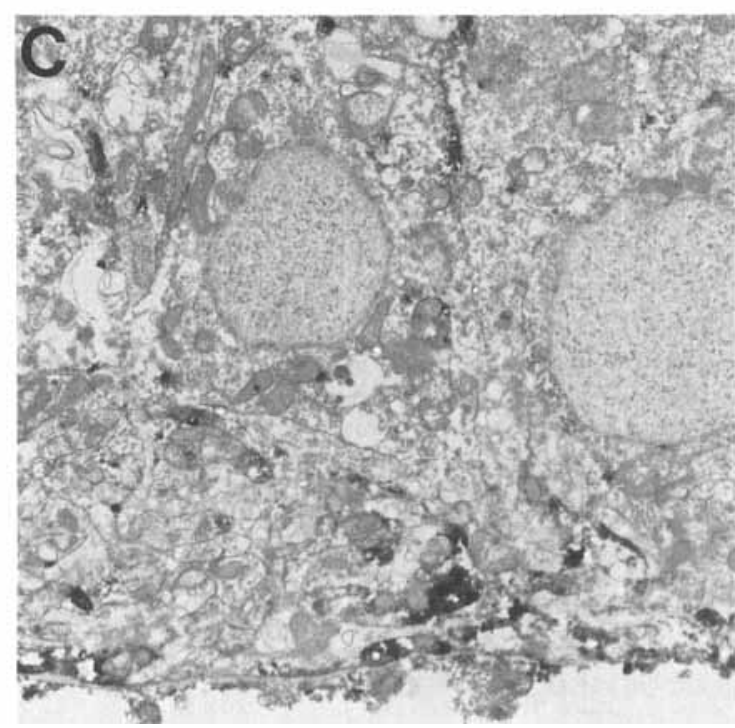

Fig. 6. Electron micrographs show a 24-hour-old embryo labeled with anti-gGFAP as a wholemount. The inset is a schematic diagram of a lateral view of the brain in a 24-hour-old embryo and depicts the pattern of labeling seen with the HNK-1 antibody (modified from Ross et al., 1992). The line gives the plane of section for the figure; A and B indicate the areas shown in panels $A$ and $C$ and panels $B$ and D, respectively. Also shown are the locations of the tracts present at 24 hours. A,B: Tracings made from electron micrographs. The stipple

though some minor differences have been reported (Dahl and Bignami, 1973; Dahl et al., 1985; Quitschke et al., 1985). The reactivity of anti-gGFAP with mammalian GFAP has previously been demonstrated on both immunoblots and tissue sections (Nona et al., 1989; Shehab et al., 1989). In the adult zebrafish, anti-gGFAP recognizes a major band of $51 \mathrm{kDa}$, which is consistent with other reports for the molecular weight of GFAP in fish (Quitschke et al., 1985; Maggs and Scholes, 1986; Levine, 1989; Nona et al., 1989). In addition, a second band was recognized at $45 \mathrm{kDa}$, which is consistent with other reports on fish (Dahl et al., 1985; Quitschke et al., 1985; Levine, 1989; Cohen et al., 1993). More than one form of GFAP has also been

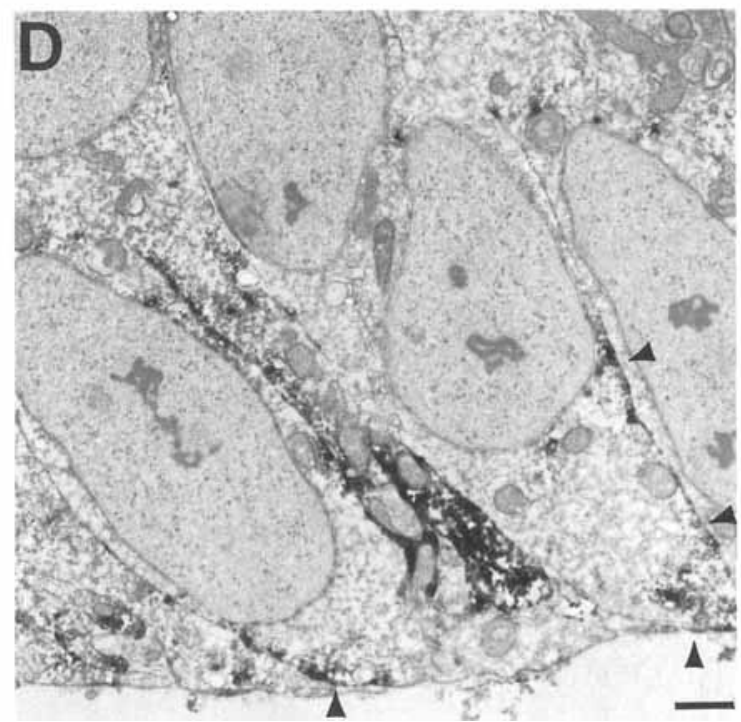

represents the GFAP label; the thinner lines represent nuclei. The region in A contains many more smaller labeled and unlabeled processes than the region in B. C,D: Electron micrographs of the regions boxed in A and B, respectively. Arrowheads in D point to label located adjacent to cell membranes. DVDT, dorsoventral diencephalic tract; MLF, medial longitudinal fasciculus; POC, postoptic commissure; TAC, tract of the anterior commissure; $\mathrm{TPC}$, tract of the posterior commissure. Scale bars $=3 \mu \mathrm{m}$ for A,B, $1 \mu \mathrm{m}$ for $\mathrm{C}, \mathrm{D}$.

observed in Xenopus (Szaro and Gainer, 1986) and axolotl (Holder et al., 1990), and it has been suggested that GFAP may exist in more than one form in animals that retain radial glia throughout life (Holder et al., 1990).

By using GFAP expression as a marker to distinguish presumptive glia from other radially oriented neuroepithelial cells, our results improve upon earlier studies that identified cells contacted by growing axons as neuroepithelial or "primitive glia" (Singer et al., 1979; Silver, 1984; Kuwada, 1986; Wilson and Easter, 1991). It is unclear whether cells labeled by GFAP in this study are "primitive" or analogous to radial glia found in the adult. In mammals, the transition from immature to mature glial forms is 


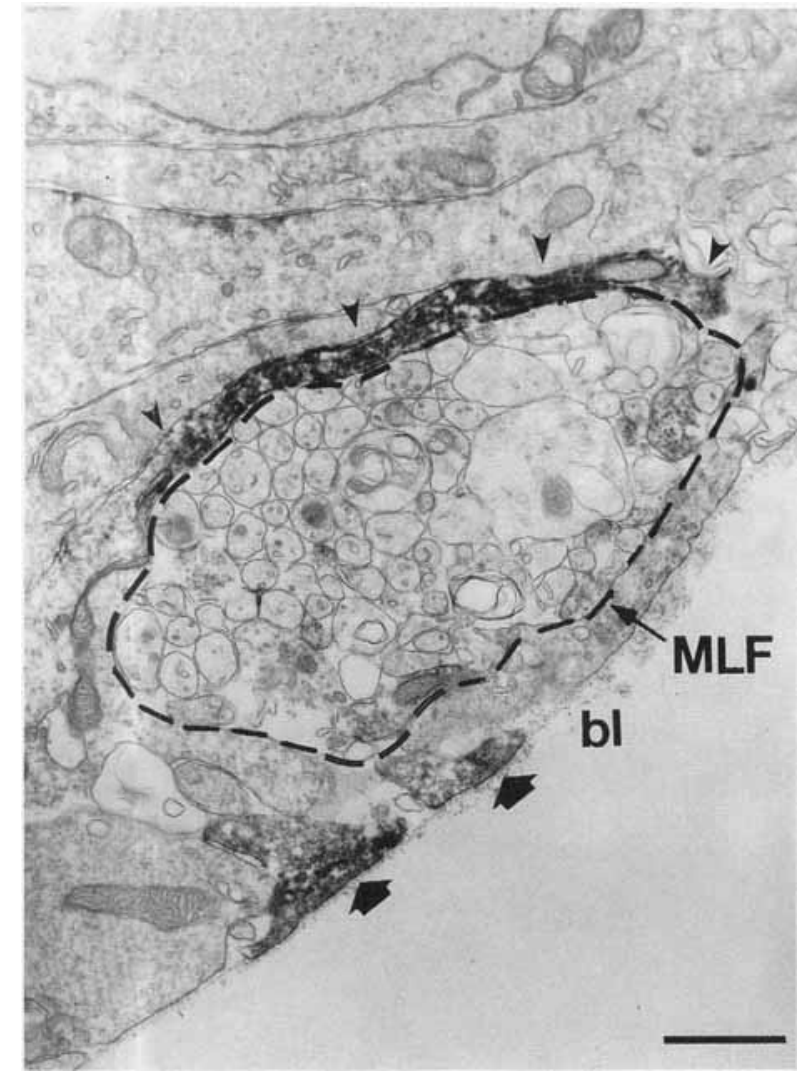

Fig. 7. Electron micrograph shows a transverse section through the hindbrain of a 24-hour-old embryo labeled with anti-gGFAP as a wholemount. Axons in the medial longitudinal fasciculus (MLF; outlined by the dashed line) are separated from the basal lamina (bl) by both labeled (arrows) and unlabeled endfeet. Medially, a GFAP-positive process separates the MLF from the cellular region of the brain (arrowheads). v, ventricle. Scale bar $=2 \mu \mathrm{m}$.

correlated with a change from expression of the intermediate filament vimentin to GFAP (Bovolenta et al., 1984; Stichel et al., 1991; Elmquist et al., 1994). No such change has been reported in fish. Thus, whereas the expression of GFAP may be an indicator of glial phenotype, it may not distinguish between immature and mature glial forms. Moreover, the absence of GFAP immunoreactivity cannot be used to identify cells as nonglial.

In a previous study on GFAP immunoreactivity in zebrafish, labeling was reported in radial glia in the spinal cord only after 60 hours (van Raamsdonk et al., 1984). Although we did not focus on the spinal cord, we noted GFAP labeling much earlier than 60 hours (e.g., Fig. 8, 48 hours). We believe the discrepancy in the time of onset is attributable to the different antibodies used. The antibody used in the earlier study was generated against GFAP isolated from bovine brain and reacted with a $49-\mathrm{kDa}$ band on Western blots of cytoskeletal proteins from fish spinal cord. The antibodies we used were raised against fish and recognized a band of $51 \mathrm{kDa}$, which others have identified as fish GFAP. For these reasons, we believe our results more accurately reflect the expression of GFAP in the zebrafish.

\section{Cellular distribution of GFAP}

In the brain, GFAP did not label radial cells in their entirety; rather, GFAP immunoreactivity was distributed in processes and endfeet located superficially. In amphibians, localized expression of GFAP in the distal portion of cells has been reported in both adult spinal cord (Miller and Liuzzi, 1986; Holder et al., 1990) and embryonic brain (Godsave et al., 1986; Szaro and Gainer, 1988; Messenger and Warner, 1989). In addition, vimentin, which labels radial glia in the embryonic chick tectum, becomes localized to the distal portion of radial cells (Vanselow et al., 1989). The restricted distribution of intermediate filament proteins within radial cells is interesting in regard to the location of developing tracts. The earliest tracts are located superficially and therefore occupy regions containing glial endfeet. It is possible that the localization of intermediate filaments in the endfeet of radial glial cells may be important for initial axon outgrowth, for instance, by providing structural support to cells on which growth cones extend or by anchoring surface proteins that may function in axonal pathfinding (e.g., laminin: Letourneau et al., 1988; NCAM: Silver and Rutishauser, 1984). The mechanism by which intermediate filaments are localized intracellularly is not known, but it is likely that it involves interaction with the extracellular environment.

In contrast to the restricted distribution of GFAP immunoreactivity in superficially located endfeet and processes in the embryonic brain, GFAP immunoreactivity is distributed throughout radial glia in the adult. For example, in the visual system, anti-gGFAP labels radial glia and ependymal glial profiles in the tectum, parallel processes in the optic tract, and Müller glia in the retina (Nona et al., 1989). It is interesting to speculate that the changing distribution of GFAP immunoreactivity may reflect a differential expression of the two GFAP moieties revealed in the immunoblots. Curiously, although GFAP is normally thought to be absent from fish optic nerve (Dahl et al., 1985; Maggs and Scholes, 1986; Levine, 1989; Nona et al., 1989; personal observation, but see also Blaugrund et al., 1991), GFAP is expressed in the goldfish optic nerve following injury (Stafford et al., 1990; Levine, 1993), and antibodies to GFAP selectively label glia in the ventral fiber bundle in the adult goldfish and cichlid (Nona et al., 1992; Scholes et al., 1992). The appearance of GFAP-immunoreactive glia at the growing margin of the optic nerve is reminiscent of the patterns seen in the embryo (J. Scholes, personal communication); therefore, these cells may reflect a bit of the embryo in the adult. The possibility that cells such as those associated with growth and/or regeneration express GFAP moieties different than those in mature glia is an area for further investigation.

\section{Neuron-glia interactions}

The late restriction of the GFAP-positive processes to regions containing tracts suggests an active interaction between these processes and axons. The interdependence of neurons and glia during development has most clearly been demonstrated for mammalian cells in vitro. Neurons induce glial differentiation in cerebellar cultures by a membranemediated mechanism (Hatten, 1985, 1987), and cortical radial glia undergo neuron-dependent morphological and immunocytochemical transformations in culture (Culican et al., 1990). Indeed, direct cell-cell interactions between cerebellar glia and granule cells, visualized by using timelapse video microscopy, demonstrated that the growing tips of astroglial processes interact with neurons, resulting in the stable association of neurons and glia (Mason et al., 1988). The correspondence of GFAP-positive cells with 

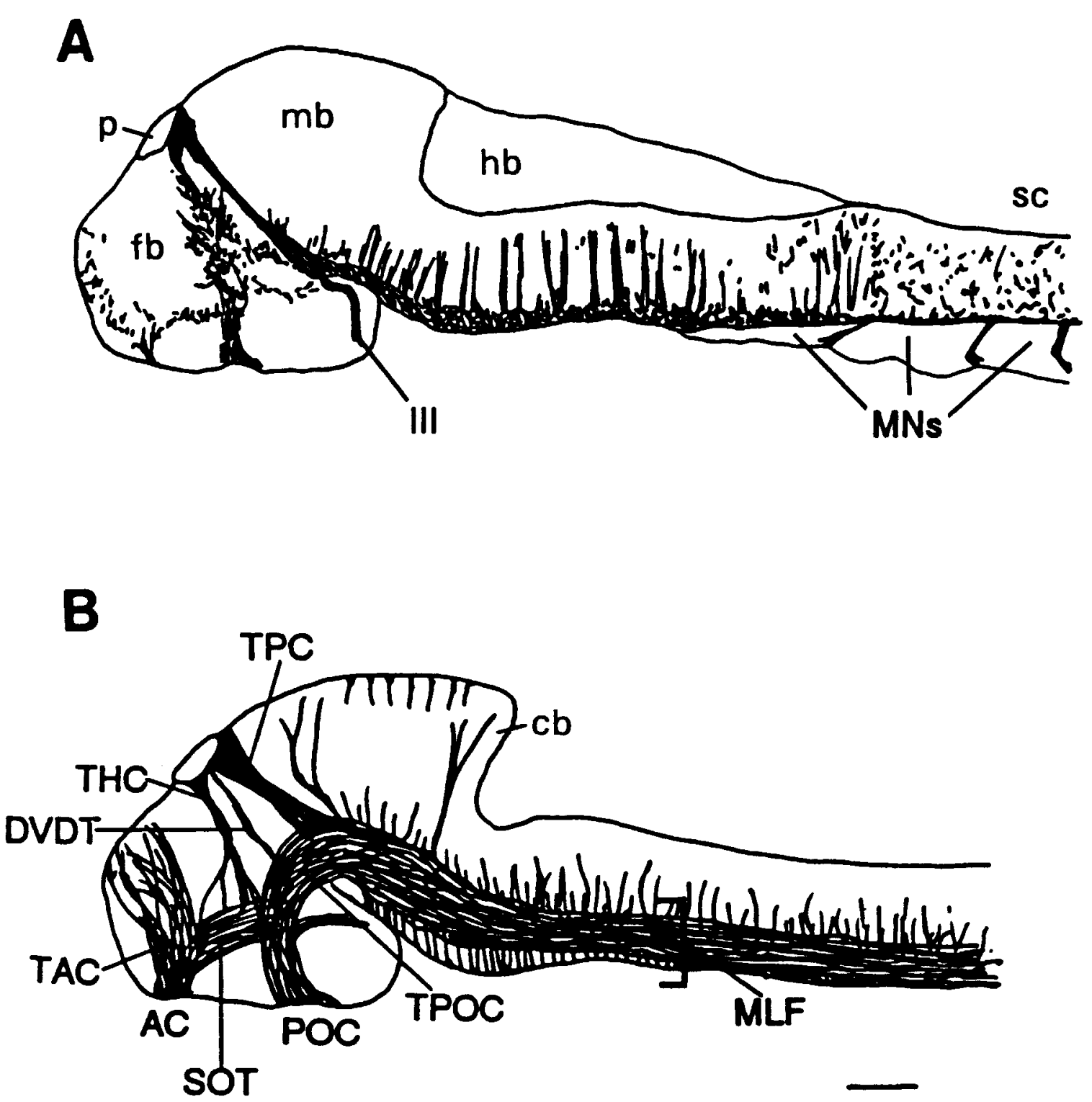

Fig. 8. Zebrafish embryos 48-hours-old are immunolabeled for GFAP (A) and axons (B). Lateral views are depicted, with anterior to the left and dorsal up. A: Camera lucida drawing shows a zrf-1-labeled wholemount. The labeled motor nerves are located on a piece of muscle and skin not dissected away from the embryo. Two types of GFAPpositive processes are observed: radial cells oriented perpendicularly to the surface of the brain and labeled processes oriented parallel to axons. The endfeet of radial cells viewed along their long axis give the tracing its "speckled" appearance (e.g., in the caudal hindbrain and spinal cord). In the hindbrain, the dorsoventrally oriented label corresponds to

tracts observed in this study may reflect a similar stable association of neurons and glia in the developing zebrafish. In addition, the appearance of GFAP-positive cells in the peripheral motor nerves and the presence of labeled cells in parallel to axons in the dorsal and ventral commissures at 48 hours suggest that the development of GFAP immunoreactivity in these cells follows axonal contact.

Electron microscopic observations suggest that GFAPpositive endfeet are altered by axonal contact. At 24 hours,
GFAP-positive processes located at segment borders. B: Schematic drawing shows HNK-1-positive tracts. Comparison of A and B indicates that GFAP-positive processes are concentrated in regions containing tracts. AC, anterior commissure; cb, cerebellum; DVD'T, dorsoventral diencephalic tract; $\mathrm{fb}$, forebrain; hb, hindbrain; mb, midbrain; MLF, medial longitudinal fasciculus; MNs, motor nerves; $p$, pineal; POC, postoptic commissure; sc, spinal cord; SOT, supraoptic tract; TAC, tract of the anterior commissure; THC, tract of the habenular commissure; TPOC, tract of the postoptic commissure; TPC, tract of the posterior commissure; III, oculomotor nerve. Scale bar $=50 \mu \mathrm{m}$. two types of labeled processes were observed: wide, closely apposed columnar endfeet, and thinner, more loosely packed processes (Fig. 6). The former were present where no axons had grown, and the latter were found in tracts. We suggest that the columnar endfeet were transformed into the filamentous ones by contact with axons or growth cones. Changes in the morphology of cells contacting axons are consistent with observations of the environment through which pioneers of the dorsoventral diencephalic tract 

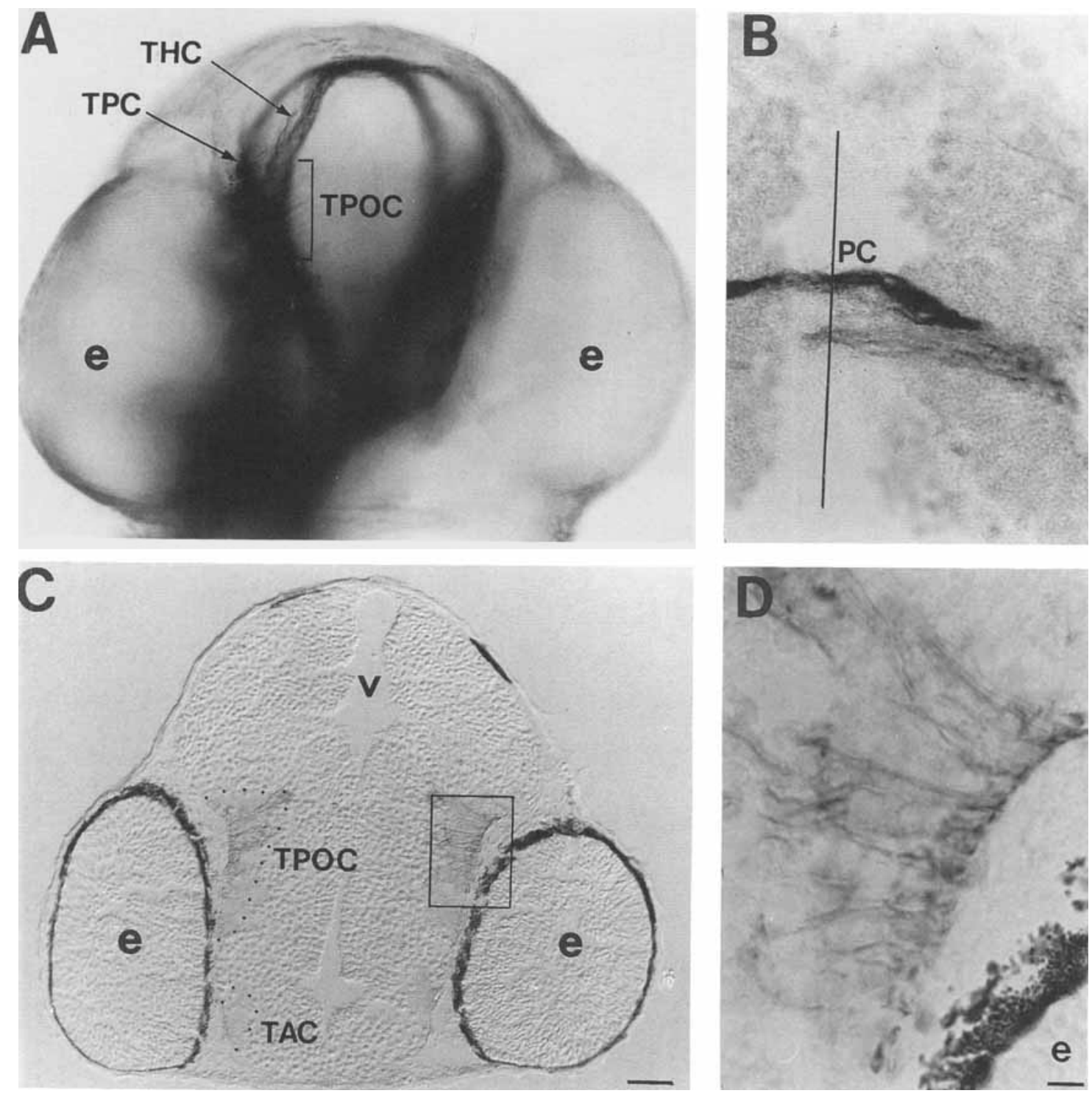

Fig. 9. Zrf-1 (A,B) and anti-gGFAP (C,D) labeling in 48-hour-old embryos. A: Frontal view of a wholemounted embryo tilted slightly to the right. The orientation of the figure is indicated by the dashed line and arrow in Figure 2. Zrf-1 labels processes parallel to axons in the tract of the posterior commissure (TPC) and the tract of the habenular commissure (THC). The bracket indicates radial processes (slightly out of focus) in the tract of the postoptic commissure (TPOC). B: Tangential section through the posterior commissure (PC) of an embryo labeled with zrf-1 as a wholemount, then sectioned and counterstained.

(DVDT) extend (Wilson and Easter, 1991). In that study, cells contacting the DVDT pioneer possessed more and thinner processes than cells located either lateral to or ahead of the growth cone, suggesting that the morphology of the columnar endfeet was altered by the passage of the growth cone. The fact that later axons grew preferentially in the same region suggests that the more loosely packed processes may provide a more hospitable enviornment for axonal growth than the columnar endfeet. This suggestion is reinforced by recent work on the development of the optic tract in zebrafish (Burrill and Easter, 1995). Optic axons grow toward the tectum in an "pretract" consisting of
Anterior is up; the midline is indicated by the solid line. Labeled processes oriented parallel to axons in the $\mathrm{PC}$ are seen crossing the dorsal midline. C: Frozen section labeled with anti-gGFAP. The plane of section is indicated in Figure 2. Radially oriented processes are located in the TPOC; the tract of the anterior commissure (TAC) appears unlabeled. D: Detail of the box in C. Densely labeled endfeet lie along the superficial edge of the brain in the region of the TPOC. e, eye $\mathrm{v}$, ventricle. Scale bars $=25 \mu \mathrm{m}$ for A,C, $10 \mu \mathrm{m}$ for B,D.

loosely packed processes from both axons and neuroepithelial cells adjacent to the TPOC rather than by fasciculating along axons in the TPOC. The anatomical texture of this pretract resembles that of the GFAP-positive regions of early tracts (Fig. 6C).

At 48 hours, GFAP-positive columnar endfeet are no longer present, as all the GFAP is in the finer processes associated with tracts, suggesting that the maintenance of GFAP expression may be dependent on axonal contact. The association of GFAP-positive processes with tracts at 48 hours is in stark contrast to the more widespread distribution of GFAP immunoreactivity seen at 15 and 24 hours. If 

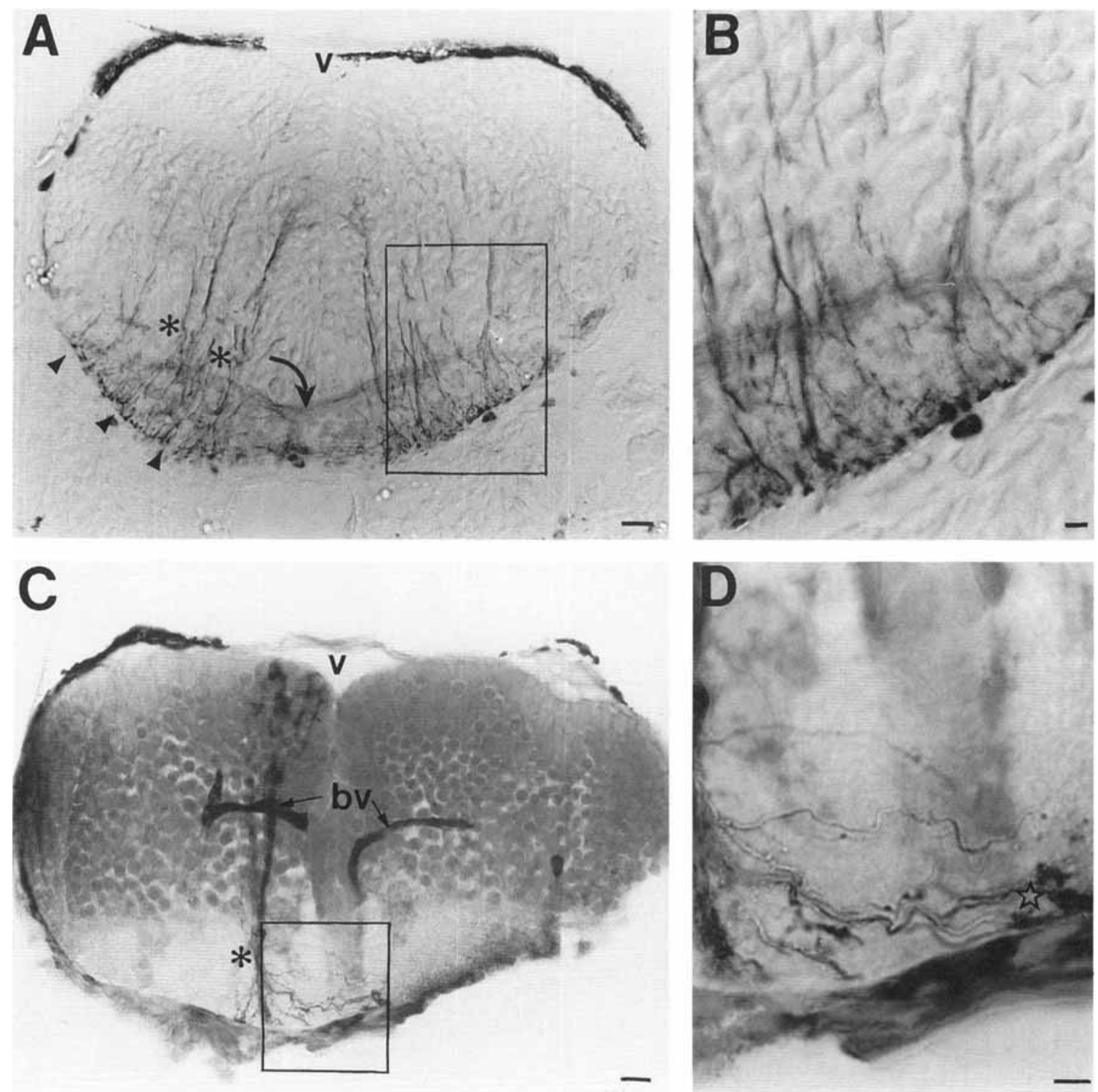

Fig. 10. Anti-gGFAP- and DiT-labeled processes in the hindbrain of 48-hour-old embryos reveal both radially and transversely oriented processes. A: Frozen section through the caudal hindbrain of a 48-hourold embryo labeled with anti-gGFAP. The plane of section is indicated in Figure 2. Arrowheads point to endfeet in the MLF. Labeled processes crossing the midline are indicated by the arrow and deep labeled processes by the asterisks. B: Detail of boxed area in A. C,D: DiI-labeled cells in the hindbrain. DiI was applied to the ventricular surface in a

GFAP expression is used as an indicator of glial phenotype, this raises the question of what becomes of GFAPexpressing glial cells at 15 and 24 but not at 48 hours. One possibility is that they die in the absence of axonal contact. This seems unlikely because examination of the brain at both the light and electron microscopic levels does not reveal extensive cell death between 24 and 48 hours. Another possibility is that they cease expressing GFAP transiently and resume expression later on, thus maintaining their glial identity. Alternatively, they may remain pluripotent and assume a neuronal fate. Unlike what has been proposed for radial glial cells in mammalian cerebral whole dissected embryo that was then sectioned and counterstained. The section is from a region of the brain similar to the section shown in A. C: DiI-labeled cells extend dorsoventrally from the ventricular surface. The processes are located deep in the brain in regions that contain GFAP-positive processes (asterisks in A and C). D: Detail of region boxed in $\mathrm{C}$. DiI-labeled processes cross to the contralateral side where some terminate in growth cone-like expansions (star). bv, blood vessel. Scale bars $=10 \mu \mathrm{m}$ in A,C, $5 \mu \mathrm{m}$ in B,D.

cortex (Ramón y Cajal, 1911; Schmechel and Rakic, 1979; Culican et al., 1990) and chick optic tecta (Gray and Sanes, 1992), there is no evidence for radial GFAP-positive cells transforming into astrocytes in the zebrafish.

\section{Glial cells and axonal guidance}

In the zebrafish, as in many other systems, axons follow highly specific and stereotyped pathways. During development, tracts form in contact with the endfeet of neuroepithelial or primitive glial cells, suggesting that growing axons may be guided to, and maintained at, the superficial surface 

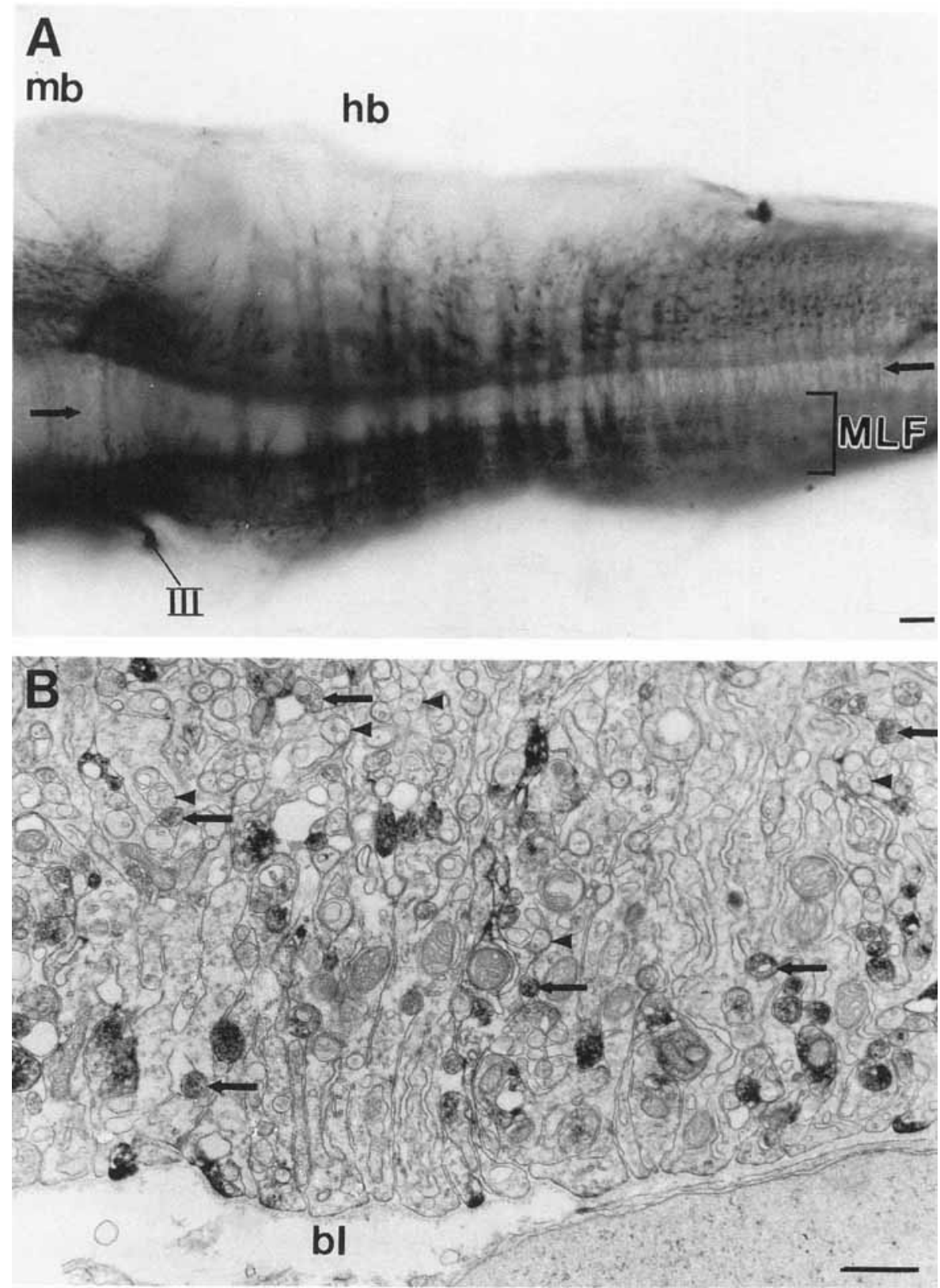

Fig. 11. GFAP-positive processes in the hindbrain of 48-hour-old embryos. A: Wholemount labeled with zrf-1. Anterior is to the left. The dorsal side of the embryo is tilted away from the reader, with the ventral midline indicated by the arrows. Bands of GFAP-positive processes cross the ventral midline. Dark, rostrocaudally labeled processes are located in the MLF, and radial cells viewed along their long axis appear as black dots. B: Electron micrograph shows a sagittal

of the brain (Singer et al., 1979; Silver et al., 1982; Kuwada, 1986; Easter and Taylor, 1989; Wilson et al., 1990; Easter et al., 1994). Because these observations were based on morphological criteria alone, the identification of the cells contacted by growth cones remained ambiguous. Our results indicate that neuroepithelial endfeet contacted by growing axons contain GFAP and are therefore glial.

The axonal guidance cues provided by endfeet during axonal outgrowth must be both general and specific. The section through the hindbrain of an embryo labeled with anti-gGFAP as a wholemount. Transversely sectioned labeled processes are interspersed among unlabeled commissural axons. Examples of GFAPpositive labeled processes and unlabeled axons are indicated by the arrows and arrowheads, respectively. bl, basal lamina; hb, hindbrain; mb, midbrain; MLF, medial longitudinal fasciculus; III, oculomotor nerve. Scale bars $=10 \mu \mathrm{m}$ in $\mathrm{A}, 1 \mu \mathrm{m}$ in $\mathrm{B}$.

general neural cell adhesion molecule, NCAM, is present on neuroepithelial endfeet along the optic pathway in chick, suggesting that guidance of optic axons is at least in part influenced by an adhesive pathway along the margin of the brain (Silver and Rutishauser, 1984). A similar mechanism may be present in zebrafish because NCAM appears to be associated with the glial endfeet identified in this study (unpublished observation). The initial widespread distribution of GFAP immunoreactivity is consistent with the idea 

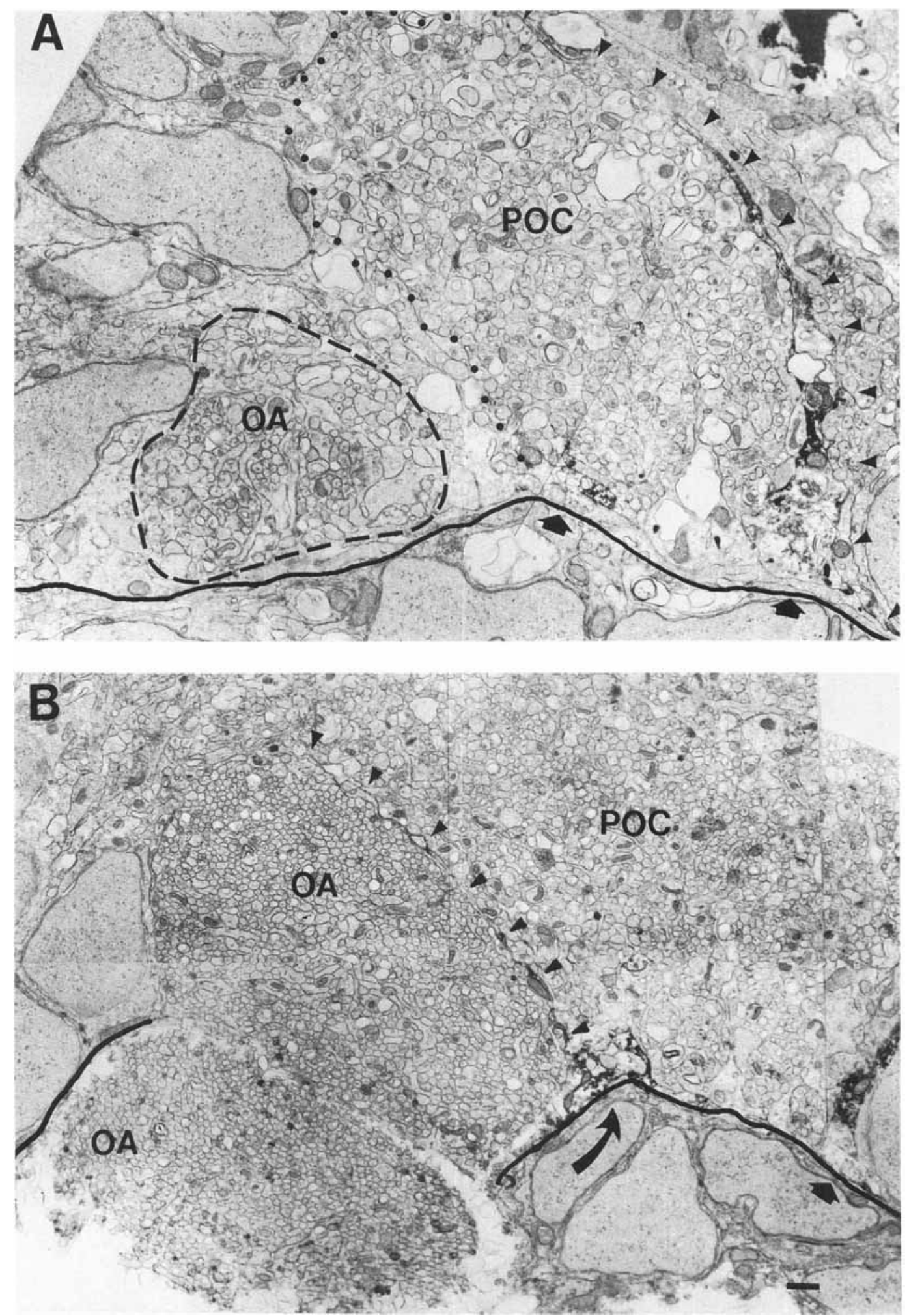

Fig. 12. Electron micrographs show postoptic commissure (POC)/ optic chiasm junction at 37 hours (A) and 48 hours (B) from wholemounts labeled with anti-gGFAP. Sagittal plane, dorsal up, anterior left. A: The optic axons from the two eyes are outlined by the dashed line, and the anterior edge of the POC is indicated by the dots. The optic axons (OA) are separated from the POC by a GFAP-negative cellular region. GFAP-positive processes and endfeet are located on the superfcial and anterior edge of the POC (arrowheads). The ventral surface of the brain is outlined by the solid black line. B: Optic axons are separated from axons in the POC by a thin GFAP-positive process (arrowheads). The thin process joins a large labeled endfoot along the superficial surface of the brain (curved arrow). A GFAP-positive endfoot and process separates the posterior edge of the POC from the cellular region of the brain (fat arrow). The solid black line outlines the edge of the brain. Scale bar $=1 \mu \mathrm{m}$. 
that GFAP-positive endfeet, like NCAM, helps provide a permissive substrate for axon outgrowth. The permissiveness of glial substrates for axon outgrowth is well established (Noble et al., 1984, Fallon, 1985); the resolution of the location and nature of more specific cues at the superficial surface remains to be elucidated.

In addition to GFAP-positive radial cells and endfeet, GFAP-positive processes oriented perpendicular to tracts were observed in the dorsal and ventral commissures. These processes are reminiscent of the glial "sling" in the developing corpus collosum (Silver et al., 1982) and the presence of thick vimentin-positive processes oriented in the direction of axon ingrowth in the developing mouse cerebellum (Bovolenta et al., 1984). The presence of transient glial processes in developing tracts suggests that axons grow through environments different, or at least having different cytoskeletal components, than those that support mature axons (Bovolenta et al., 1984).

In contrast to providing permissive substrates for axonal growth, glial cells may form boundaries inhibiting axons from entering inappropriate regions (Silver et al., 1987; Caroni and Schwab, 1988; Snow et al., 1990; Carpenter and Bastiani, 1991; Silver et al., 1993). During development, transient glial boundaries surround functional groups of neurons, suggesting that they contribute to pattern formation in the central nervous system (for review, see Steindler, 1993). The association of GFAP-positive cells with the developing tracts, and in particular the presence of glial processes separating axons from other tracts or cellular regions of the brain in this study, supports such a function. The presence of glial palisades at the boundaries of rhombomeres (present study; Trevarrow et al., 1990) strongly suggests that in the zebrafish glia may be important in the subdivision of the hindbrain. Dorsoventrally oriented glial fibers have also been associated with axonal bundles observed in the spinal cord, medulla, and pons of mouse and rat (Bitner et al., 1987).

The identification of specialized midline glial systems associated with decussating axons in the spinal cord (TessierLavigne et al., 1988; McKanna and Cohen, 1989; Kuwada et al., 1990, Yaginuma and Oppenheim, 1991), brain (Van Hartesveldt et al., 1986; Mori et al., 1990; Silver et al., 1993), and optic chiasm (Marcus et al., 1995) suggests that glia play a role in the organization of axons at the midline. In the zebrafish brain, GFAP-positive processes appear at the midline after axons have decussated and therefore do not appear to direct axonal growth across the neuraxis. Although it is possible that prior to their expression of GFAP, midline glia are present and provide guidance cues for crossing axons, in agreement with our observations, recent work in Drosophila suggests that midline glia do not play the key role in the guidance of growth cones across the midline. Instead, midline glia are involved in the normal separation of axon fascicles in the ventral commissures (Klämbt et al., 1991). The development of GFAP-positive cells between optic axons and axons in the postoptic commissure only after the first optic axons have already crossed the midline is consistent with a role for GFAP-positive processes in maintaining a border between these distinct sets of axons rather than a function in directed axon outgrowth across the midline.

\section{ACKNOWLEDGMENTS}

We thank Drs. J.D. Burrill, L.S. Ross, J. Scholes, and S.W. Wilson for comments and useful discussions; Ms. C.
Malinoski for her technical expertise; and Drs. S. Nona, M. Westerfield, and C. Stern for providing antibodies. This work was supported by NIH research grant EY-00168 to S.S.E. and NIH training grant EY-07022 to R.C.M.

\section{LITERATURE CITED}

Bastiani, M.J, and C.S. Goodman (1986) Guidance of neuronal growth cones in the grasshopper embryo. III. Recognition of specific glial pathways. J. Neurosci. 6:3542-3551.

Bitner, C., S. Benjelloun-Touimi, and P. Dupouey (1987) Palisading pattern of subpial astroglial processes in the adult rodent brain: Relationship between the glial palisading pattern and the axonal and astroglial organization. Dev. Brain Res. 37:167-178.

Blaugrund, E., I., Cohen, Y. Shani, and M. Schwartz (1991) Glial fibrillary acidic protein in the fish optic nerve. Glia 4:393-399.

Bovolenta, P., and C.A. Mason (1987) Growth cone morphology varies with position in the developing mouse visual pathway from retina to first visual targets. J. Neurosci. 7:1447-1460.

Bovolenta, P., R.K.L. Liem, and C.A. Mason (1984) Development of cerebellar astroglia: transitions in form and cytoskeletal content. Dev. Biol. 102:248-259.

Bovolenta, P., R.K.H. Liem, and C.A. Mason (1987) Glial filament protein expression in astroglia in the mouse visual pathway. Dev. Brain Res. 33:113-126.

Burrill, J.D., and S.S. Easter, Jr. (1991) The relationship of optic growth cones to the tract of the postoptic commissure in the developing zebrafish brain. Soc. Neurosci. Abstr. 17:39.

Burrill, J.D., and S.S. Easter, Jr. (1995) The first retinal axons and their microenvironment in zebrafish: cryptic pioneers and the pre-tract. J. Neurosci. 15:2935-2947.

Caroni, P., and M.E. Schwab (1988) Two membrane protein fractions from rat central myelin with inhibitory properties for neurite growth and fibroblast spreading. J. Cell Biol. 106:1281-1288.

Carpenter, E.M., and M.J. Bastiani (1991) Developmental expression of REGA-1, a regionally expressed glial antigen in the central nervous system of grasshopper embryos. J. Neurosci. 11:277-286.

Chitnis, A.B., and J.Y. Kuwada (1990) Axonogenesis in the brain of zebrafish embryos. J. Neurosci. 10:1892-1905.

Chiu, F.-C., and W.T. Norton (1982) Bulk preparation of CNS cytoskeleton and the separation of individual neurofilament proteins by gel filtration Dye-binding characteristics and amino acid compostions. J. Neurochem 39: $1252-1260$.

Cochard, P., and D. Paulin (1984) Initial expression of neurofilaments and vimentin in the central and peripheral nervous system of the mouse embryo in vivo. J. Neurosci. 4:2080-2094.

Cohen, I., Y. Shani, and M. Schwartz (1993) Cloning and characteristics of fish glial fibrillary acidic protein: Implications for optic nerve regeneration. J. Comp. Neurol. 334:431-443.

Collelo, R.J., and R.W. Guillery (1992) Observations on the early development of the optic nerve and tract of the mouse. J. Comp. Neurol. $317: 357-378$

Culican, S.M., N.L. Baumrind, M. Yamamoto, and A.L. Pearlman (1990) Cortical radial glia: Identification in tissue culture and evidence for their transformation to astrocytes. J. Neurosci. 10:684-692.

Dahl, D., and A. Bignami (1973) Immunochemical and immunofluorescence studies of the glial fibrillary acidic protein in vertebrates. Brain Res. 61:279-293.

Dahl, D., C.J. Crosby, J.S. Sethi, and A. Bignami (1985) Glial fibrillary acidic (GFA) protein in vertebrates: Immunofluorescence and immunoblotting study with monoclonal and polyclonal antibodies. J. Comp. Neurol. 239:75-88.

Easter, S.S. Jr., and J.S.H. Taylor (1989) The development of the Xenopus retinofugal pathway: Optic fibers join a pre-existing tract. Development 107:553-573

Easter, S.S. Jr., L.S. Ross, and A. Frankfurter (1993) Initial tract formation in the mouse brain. J. Neurosci. 13:285-299.

Easter, S.S. Jr., J.D. Burrill, R.C. Marcus, L.S. Ross, J.S.H. Taylor, and S.W. Wilson (1994) Initial tract formation in the vertebrate brain. Prog. Brain Res. 102:79-93.

Elmquist, J.K., J.J. Swanson, D.S. Sakaguchi, L.R. Ross, and C.D. Jacobson (1994) Developmental distribution of GFAP and vimentin in the brazilian opossum brain. J. Comp. Neurol. 344:283-296.

Eng, L.F., J.J. Vanderhaeghen, A. Bignami, and B. Gerstl (1971) An acidic protein isolated from fibrous astrocytes. Brain Res. 28:351-354. 
Fallon, J.R. (1985) Preferential outgrowth of central nervous system neurites on astrocytes and Schwann cells as compared with nonglial cells in vitro. J. Cell Biol. 100:198-207.

Godsave, S.F., B.H. Anderton, and C.C. Wylie (1986) The appearance and distribution of intermediate filament proteins during differentiation of the central nervous system, skin and notochord of Xenopus laevis. J. Embryol. Exp. Morph. 97:201-223.

Gorczyca, M.G., R.W. Phillis, and V. Budnik (1994) The role of tinman, a mesodermal cell fate gene, in axon pathfinding during the development of the transverse nerve in Drosophila. Development 120:2143-2152.

Gray, G.E., and J.R. Sanes (1992) Lineage of radial glia in the chicken optic tectum. Development 114:271-283.

Hatten, M.E. (1985) Neuronal regulation of astroglial morphology and proliferation in vitro. J. Cell Biol. 100:384-396.

Hatten, M.E. (1987) Neuronal inhibition of astroglial cell proliferation is membrane mediated. J. Cell Biol. 104:1353-1360.

Holder, N., J.D.W. Clarke, T. Kamalati, and E.B. Lane (1990) Heterogeneity in spinal radial glia demonstrated by intermediate filament expression and HRP labelling. J. Neurocytol. 19:915-928.

Honig, M.G., and R.I. Hume (1986) Fluorescent carbocyanine dyes allow living neurons of identified origin to be studied in long-term cultures. J. Cell Biol. 103:171-187.

Jacobs, J.R. (1993) Perturbed glial scaffold formation precedes axon tract malformation in Drosophila mutants. J. Neurobiol. 24:611-626.

Jacobs, J.R., and C.S. Goodman (1989) Embryonic development of axon pathways in the Drosophila CNS. I. A glial scaffold appears before the first growth cones. J. Neurosci. 9:2402-2411.

Joosten, E.A.J., and A.A.M. Gribnau (1989) Astrocytes and guidance of outgrowing corticospinal tract axons in the rat. An immunocytochemical study using anti-vimentin and anti-glial fibrillary acidic protein. Neuroscience 31:439-452.

Klämbt, C., J.R. Jacobs, and C.S. Goodman (1991) The midline of the Drosophila central nervous system: A model for the genetic analysis of cell fate, cell migration, and growth cone guidance. Cell 64:801-815.

Kruse, J., R. Mailhammer, H. Wernecke, A. Faissner, I. Sommer, C. Gordis, and M. Schachner (1984) Neural cell adhesion molecules and myelinassociated glycoprotein share a common carbohydrate moiety recognized by monoclonal antibodies L2 and HNK-1. Nature 311:153-155.

Kuwada, J.Y. (1986) Cell recognition by neuronal growth cones in a simple vertebrate embryo. Science 233:740-746.

Kuwada, J.Y., R.R. Bernhardt, and A.B. Chitnis (1990) Pathfinding by identified growth cones in the spinal cord of zebrafish embryos. J. Neurosci. 10:1299-1308.

Laemmli, U.K. (1970) Cleavage of structural proteins during the assembly of the head of bacteriophage T4. Nature 227:680-685.

Letourneau, P.C., A.M. Madsen, S.L. Palm, and L.T. Furcht (1988) Immunoreactivity for laminin in the developing ventral longitudinal pathway of the brain. Dev. Biol. 125:135-144.

Levine, R.L. (1989) Organization of astrocytes in the visual pathways of the goldfish: an immunohistochemical study. J. Comp. Neurol, 285:231-245.

Levine, R.L. (1993) Axon dependent glial changes during optic fiber regeneration in the goldfish. J. Comp. Neurol. 333:543-553.

Levitt, P., and P. Rakic (1980) Immunoperoxidase localization of glial fibrillary acidic protein in radial glial cells and astrocytes of the developing rhesus monkey brain. J. Comp. Neurol. 193:417-448.

Maggs, A., and J. Scholes (1986) Glial domains and nerve fiber patterns in the fish retinotectal pathway. J. Neurosci. 6:424-438.

Marcus, R.C., and S.S. Easter, Jr. (1990) Appearance and distribution of GFAP immunoreactivity in the embryonic zebrafish CNS. Soc. Neurosci. Abstr. 16:310.

Marcus, R.C., J.D. Burrill, and S.S. Easter, Jr. (1990) GFAP immunoreactive processes in tracts of the developing pathway in the embryonic zebrafish. Invest. Ophth, Vis. Sci. 32:925.

Marcus, R.C., R. Blazeski, P. Godement, and C.A. Mason (1995) Retinal axon divergence in the optic chiasm: Uncrossed axons diverge from crossed axons within a midline glial specialization. J. Neurosci. 15:3716-3729.

Mason, C.A., J.C. Edmondson, and M.E. Hatten (1988) The extending astroglial process: Development of glial cell shape, the growing tip, and interactions with neurons. J. Neurosci. 8:3124-3134.

McKanna, J.A., and S. Cohen (1989) The EGF receptor kinase substrate p35 in the floorplate of the embryonic rat CNS. Science $243: 1477-1479$

Mendelson, B. (1986) Development of reticulospinal neurons of the zebrafish. II. Early axonal outgrowth and cell body position. J. Comp. Neurol. 251:172-184
Messenger, N.J., and A.E. Warner (1989) The appearance of neural and glial cell markers during early development of the nervous system in the amphibian embryo. Development 107:43-54

Metealfe, W.K., P.Z. Myers, B. Trevarrow, M.B. Bass, and C.B. Kimmel (1990) Primary neurons express the L2/HNK-1 carbohydrate during early development in the zebrafish. Development 110:491-504

Miller, R.H., and F.J. Liuzzi (1986) Regional specialization of the radial glial cells of the adult frog spinal cord. J. Neurocytol, 15:187-196.

Mori, K., J. Ikeda, and O. Hayaishi (1990) Monoclonal antibody R2D5 reveals midsagittal radial glial system in postnatally developing and adult brainstem. Proc. Natl. Acad. Sci. USA 87:5489-5493.

Myers, P.Z., J.S. Eisen, and M. Westerfield (1986) Development and axonal outgrowth of identified motoneurons in the zebrafish. J. Neurosci $6: 2278-2289$

Noble, M., J. Fok-Seang, and J. Cohen (1984) Glia are a unique substrate for the in vitro growth of central nervous system neurons. J. Neurosci 4:1892-1903

Nona, S.N., S.A.S. Shehab, C.A. Stafford, and J.R. Cronly-Dillon (1989) Glial fibrillary acidic protein (GFAP) from goldfish: Its localisation in visual pathway. Glia 2:189-200

Nona, S.N., C.A. Stafford, S.A.S. Shehab, and J.R. Cronly-Dillon (1992) GFAP as a marker for astrocytes in normal and regenerating goldfish visual system. In S. Nona, J. Cronly-Dillon, M. Ferguson, and C. Stafford (eds): Development and Regeneration of the Nervous System. London: Chapman \& Hall, pp. 97-108.

Norris, C.R., and K. Kalil (1991) Guidance of eallosal axons by radial glia in the developing cerebral cortex. J. Neurosci. 11:3481-3492.

Quitschke, W., and N. Schechter (1986) Homology and diversity between intermediate filament proteins of neuronal and nonneuronal origin in goldfish optic nerve. J. Neurochem. 46:545-555.

Quitschke, W., P.S. Jones, and N. Schechter (1985) Survey of intermediat filament proteins in optic nerve and spinal cord: Evidence for differential expression. J. Neurochem. 44:1465-1476.

Ramón y Cajal, S. (1911) Histologie du systeme nerveux de l'homme et des vertebres. Paris: Maloine.

Ross, L.S., T. Parrett, and S.S. Easter, Jr. (1992) Axonogenesis and morphogenesis in the embryonic zebrafish brain. J. Neurosci. 12:467482.

Sandell, J.H., and R.H. Masland (1988) Photoconversion of some fluorescent markers to a diaminobenzidine product. J. Histochem. Cytochem. 36:555559

Schmechel, D.E., and P. Rakic (1979) A golgi study of radial glial cells in developing monkey telencephalon: Morphogenesis and transformation into astrocytes. Anat. Embryol. 156:115-152.

Scholes, J., A. Maggs, and A.J. Dowding (1992) Glial/axonal pattern formation in the fish optic nerve. In S. Nona, J. Cronly-Dillon, M. Ferguson and C. Stafford (eds): Development and Regeneration of the Nervous System. London: Chapman \& Hall, pp. 109-143.

Sechrist, J., and M. Bronner-Fraser (1991) Birth and differentiation of reticular neurons in the chick hindbrain: Ontogeny of the first neuronal population. Neuron 7:947-963.

Shehab, S.S., C.A. Stafford, S.N. Nona, and J.R. Cronly-Dillon (1989) Anti-goldfish glial fibrillary acidic protein (GFAP) recognizes astrocytes from rat CNS. Brain Res. 504:343-346.

Silver, J. (1984) Studies on the factors that govern directionality of axonal growth in the embryonic optic nerve and at the chiasm of mice. J. Comp. Neurol. 223:238-251.

Silver, J., and U. Rutishauser (1984) Guidance of optic axons in vivo by a preformed adhesive pathway on neuroepithelial endfeet. Dev. Biol 106:485-499.

Silver, J., and R.L. Sidman (1980) A mechanism for the guidance and topographic patterning of retinal ganglion cell axons. J. Comp. Neurol. 189:101-111.

Silver, J., S.E. Lorenz, D. Wahlsten, and J. Coughlin (1982) Axonal guidance during development of the great cerebral commissures: Descriptive and experimental studies, in vivo, on the role of preformed glial pathways. $J$ Comp. Neurol. 210:10-29.

Silver, J., M. Poston, and U. Rutishauser (1987) Axon pathway boundaries in the developing brain. I. Cellular and molecular determinants that separate the optic and olfactory projections. J. Neurosci. 7:2264-2272.

Silver, J., M.A. Edwards, and P. Levitt (1993) Immunocytochemical demonstration of early appearing astroglial structures that form boundaries and pathways along axon tracts in the fetal brain. J. Comp. Neurol. $328: 415-436$ 
Singer, M., R.H. Nordlander, and M. Egar (1979) Axonal guidance during embryogenesis and regeneration in the spinal cord of the newt: the blueprint hypothesis of neuronal pathway patterning. J. Comp. Neurol. 185:1-22.

Snow, D.M., D.A. Steindler, and J. Silver (1990) Molecular and cellular characterization of the glial roof plate of the spinal cord and optic tectum: A possible role for a proteoglycan in the development of an axon barrier. Dev. Biol, 138:359-376.

Stafford, C.A., S.A.S. Shehab, S.N. Nona, and J.R. Cronly-Dillon (1990) Expression of glial fibrillary acidic protein (GFAP) in goldfish optic nerve following injury. Glia 3:33-42.

Steindler, D.A. (1993) Glial boundaries in the developing nervous system. Ann. Rev. Neurosci. 16:445-470.

Stichel, C.C., C.M. Muller, and K. Zilles (1991) Distribution of glial acidic protein and vimentin immunoreactivity during rat visual cortex development. J. Neurocytol. 20:97-108.

Stuermer, C.A.O. (1988) Retinotopic organization of the developing retinotectal projection in the zebrafish embryo. J. Neurosci. 8:4513-4530

Szaro, B.G., and H. Gainer (1988) Immunocytochemical identification of non-neuronal intermediate filament proteins in the developing Xenopus laevis nervous system. Dev. Brain Res. 43:207-224.

Tessier-Lavigne, M., M. Placzek, A.G.S. Lumsden, J. Dodd, and T.M. Jessell (1988) Chemotropic guidance of developing axons in the mammalian central nervous system. Nature 336:775-778.
Trevarrow, B. (1988) Early organization of neurons in the zebrafish CNS. Doctoral dissertation, University of Oregon, Eugene.

Trevarrow, B., D.L. Marks, and C.B. Kimmel (1990) Organization of hindbrain segments in the zebrafish embryo. Neuron 4:669-679.

Van Hartesveldt, C., B., Moore, and Hartman, B.K. (1986) Transient midline raphe glial structure in the developing rat. J. Comp. Neurol. 253:175184.

van Raamsdonk, W., C. Heyting, C.W. Pool, M.J. Smit-Onel, and J.L. Groen (1984) Differentiation of neurons and radial glia in the spinal cord of the teleost Brachydanio rerio (the zebrafish): An immunocytochemical study. Int. J. Dev. Neurosci. 2:471-481.

Vanselow, J., S. Thanos, P. Godement, S. Henke-Fahle, and F. Bonhoeffer (1989) Spatial arrangement of radial glia and ingrowing retinal axons in the chick optic tectum during development. Dev. Brain Res. 45:15-27.

Westerfield, M. (1989) The Zebrafish Book. Eugene: University of Oregon Press.

Wilson, S.W., and S.S. Easter, Jr. (1991) A pioneering growth cone in the embryonic zebrafish brain. Proc. Natl. Acad. Sci. USA 88:2293-2296.

Wilson, S.W., L.S. Ross, T. Parrett, and S.S. Easter, Jr. (1990) The development of a simple scaffold of axon tracts in the brain of the embryonic zebrafish, Brachydanio rerio. Development 108:121-145.

Yaginuma, H., and R.W. Oppenheim (1991) An experimental analysis of in vivo guidance cues used by axons of spinal interneurons in the chick embryo: Evidence for chemotropism and related guidance mechanisms. J. Neurosci. 11:2598-2613. 